\title{
Adsorption of Organic Dyes by TiO $@$ @Yeast-Carbon Composite Microspheres and Their In Situ Regeneration Evaluation
}

\author{
Zheng Pei, ${ }^{1}$ Zhang Kaiqiang, ${ }^{1}$ Dang Yu, ${ }^{1}$ Bai Bo, ${ }^{2}$ Guan Weisheng, ${ }^{1}$ and Suo Yourui ${ }^{2}$ \\ ${ }^{1}$ College of Environmental Science and Engineering, Chang'an University, Xian 710054, China \\ ${ }^{2}$ Northwest Plateau Institute of Biology, Chinese Academy of Sciences, Xining 810001, China \\ Correspondence should be addressed to Bai Bo; baibochina@163.com
}

Received 21 July 2014; Revised 9 September 2014; Accepted 1 October 2014

Academic Editor: Jinmei He

Copyright (c) 2015 Zheng Pei et al. This is an open access article distributed under the Creative Commons Attribution License, which permits unrestricted use, distribution, and reproduction in any medium, provided the original work is properly cited.

\begin{abstract}
$\mathrm{TiO}_{2} @ y e a s t-c a r b o n$ microspheres with raspberry-like morphology were fabricated based on the pyrolysis method. The obtained products were characterized by field emission scanning electron microscopy (FE-SEM), energy dispersive spectrometry (EDS), and X-ray diffraction (XRD). Effects of initial dye concentration and contact time on adsorption capacity of TiO ${ }_{2} @ y e a s t-c a r b o n$ for cationic dye methylene blue (MB) and anionic dye congo red (CR) were investigated. Experimental data were described by Langmuir, Freundlich, Temkin, and Koble-Corrigan isotherm models, respectively. It was found that the equilibrium data of MB adsorption were best represented by Koble-Corrigan, and CR adsorption was best described by both Freundlich and KobleCorrigan isotherm models. The kinetic data of MB and CR adsorption fitted pseudo-second-order kinetic model well. The results demonstrated that $\mathrm{TiO}_{2}$ @yeast-carbon microspheres achieved favorable removal for the cationic $\mathrm{MB}$ in comparison with that for the anionic CR. In addition, regeneration experimental results showed that $\mathrm{TiO}_{2} @ y e a s t-c a r b o n$ exhibited good recycling stability, reusability, and in situ renewability, suggesting that the as-prepared $\mathrm{TiO}_{2} @ y$ east-carbon might be used as the potential low cost alternative for recalcitrant dye removal from industrial wastewater. One possible mechanism for regenerating dye-loaded $\mathrm{TiO}_{2} @$ yeast in situ was also proposed.
\end{abstract}

\section{Introduction}

Organic dyes are widely and frequently used in various industries as textile, printing, petroleum, paper, and rubber $[1,2]$. During the manufacturing and dyeing process, a substantial amount of dyestuff is lost into water, which poses a great threat to the environment. Typically, the presence of these toxic organic compounds reduces light penetration into water, affects photosynthesis of aquatic lives, impedes the growth of microbes, creates toxicity to fish, accumulates in the food chain, and even travels long distance, causing harm not only to the place where they are produced and used but also globally [3]. Moreover, most of the organic dyes are recalcitrant and difficult to degrade because of their complex and stable aromatic molecular structure [4]. Hence, the removal or degradation of organic dyes from water bodies has become a major environmental problem. Till now, some physical or chemical strategies have been attempted to remove dye contaminants from water, including adsorption [5], advanced oxidation process (AOP) [6], membrane filtration [7], ozonation [8], and coagulationflocculation [9]. Among the above-mentioned technologies, adsorption has been proven to be one of the most efficient and reliable methods for removing dyes from aqueous solution because of its flexibility, high efficiency, ease of operation, simplicity of design, and insensitivity to toxic pollutants [10]. A wide variety of low cost and easily available materials, such as bentonite [11], fly ash [12], clay [13], active carbon [14], and agriculture wastes $[15,16]$, have been exploited for the removal of dyes from aqueous solutions.

Yeast-carbon is a porous and amorphous solid carbon material, which is derived mainly from baker's yeast. For example, Nacco and Aquarone [17] firstly reported the fabrication of yeast-carbon by carbonizing yeast cells in gasheated muffle. The prepared yeast-carbon exhibited larger surface area. Guan et al. [18] synthesized amphiphilic porous 


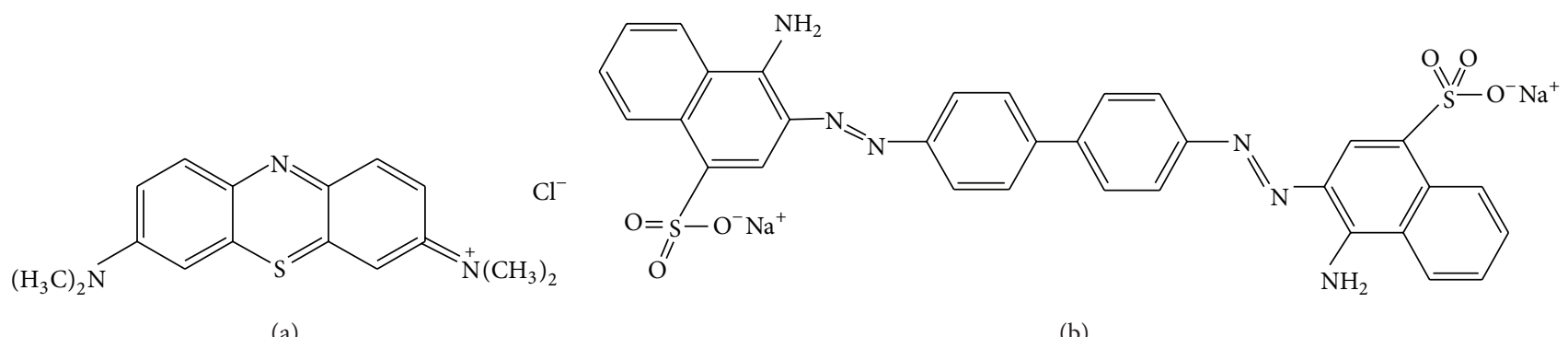

FIgure 1: The structures of dyes: (a) MB and (b) CR.

hollow carbonaceous spheres via mild hydrothermal treatment of yeast cells and further pyrolyzing. The obtained carbon spheres displayed effective sorption of phenol from water. In comparison with the great successes in the yeastcarbon synthesis, the practical application of yeast-carbon as adsorbent in wastewater treatment has still been limited because the adsorbent could get saturated easily in the adsorption process, which requires extra regeneration or complete replacement [4]. More recently, $\mathrm{TiO}_{2}$ has become a hot topic mainly for its excellent photocatalytic performance [19]. The integration of adsorption and $\mathrm{TiO}_{2}$ photocatalysis seems to offer a good solution to overcome the shortcoming of extra regeneration or complete replacement from the traditional adsorption process. In such a synergetic process, the rich pore structure of adsorbents might promote the transfer and adsorption of organic dyes, while the $\mathrm{TiO}_{2}$ could destroy dyes by photocatalytic oxidation, thus regenerating the adsorbent in situ [20].

In the previous work, we fabricated the novel $\mathrm{TiO}_{2} @ y e a s t-c a r b o n$ microsphere with raspberry-like morphology based on the pyrolysis method [21]. In the present work, as a continual job, the prepared hybrid raspberry-like $\mathrm{TiO}_{2} @$ yeast-carbon microspheres were further used as adsorbents for removal of two typical organic dyes (Methylene blue and Congo red) from aqueous solution. The adsorption equilibrium isotherms and kinetics was fully conducted. Moreover, in situ regeneration of the adsorbents was investigated, and one possible mechanism for regenerating dye-loaded $\mathrm{TiO}_{2} @ y e a s t$ in situ was also proposed.

\section{Materials and Methods}

2.1. Materials. The powdered yeast was provided by Angel Yeast Co. $\mathrm{TiO}_{2}$ with the primary particle size at $20-30 \mathrm{~nm}$ was from Degussa and was used without further purification. Absolute ethanol and double-distilled water were used throughout all the experimental procedures. Methylene blue $(\mathrm{MB})$ and Congo red (CR) were purchased from Xian Chemical Agent Company and were used as pollutants in the present work. Analytic grade sodium hydroxide $(\mathrm{NaOH})$ and sulfuric acid $\left(\mathrm{H}_{2} \mathrm{SO}_{4}\right)$ were purchased from Xi'an Chemical Agent Company.

2.2. Synthesis of $\mathrm{TiO}_{2} @$ Yeast-Carbon Microspheres. In a typical synthesis procedure, $0.1 \mathrm{~g}$ of $\mathrm{TiO}_{2}$ was dissolved in $200 \mathrm{~mL}$ of distilled water, using ultrasonic vibration for $10 \mathrm{~min}$, and the $\mathrm{pH}$ value was adjusted to approximately $9-10$ by adding dropwise sodium hydroxide $(1.0 \mathrm{~mol} / \mathrm{L})$. Then, the dispersion was stirred in magnetic stirrers for $30 \mathrm{~min}$ to facilitate particle deaggregation. In a separate vessel, $1.25 \mathrm{~g}$ yeast powder was washed with distilled water and absolute ethanol for three times, respectively. Subsequently, the yeast was dispersed in $200 \mathrm{~mL}$ of distilled water and magnetically stirred vigorously for $30 \mathrm{~min}$, and the $\mathrm{pH}$ value was adjusted to approximately 3 with sulfuric acid $(1.0 \mathrm{~mol} / \mathrm{L})$. After that, the above $\mathrm{TiO}_{2}$ and yeast cells were gathered by centrifugation from their own suspensions and redispersed in $200 \mathrm{~mL}$ of distilled water, respectively. Thereafter, $\mathrm{TiO}_{2}$ and yeast suspensions were slowly mixed with continuously magnetic stirring for $1.5 \mathrm{~h}$ at room temperature and left for $3.0 \mathrm{~h}$ without further stirring in order to ensure the formation of $\mathrm{TiO}_{2} @ y e a s t$ particles. The mixture was collected by centrifugation, washed with distilled water and absolute ethanol for three times, and then desiccated at $353 \mathrm{~K}$ for $1.0 \mathrm{~h}$. Finally, the dried $\mathrm{TiO}_{2} @ y e a s t$ particles were calcined at $573 \mathrm{~K}$ in a nitrogen pipe furnace for $1.0 \mathrm{~h}$ and cooled to room temperature. After that, $\mathrm{TiO}_{2} @ y e a s t-$ carbon hybrid microspheres were obtained. For comparison, the yeast-carbon was prepared by similar method without adding $\mathrm{TiO}_{2}$.

2.3. Characterization. Surface structure and morphology of samples were observed by using Philip XL-30 field emission scanning electron microscope (FE-SEM). Detailed composition characterization was carried out with energy-dispersive spectroscopy (EDS) analysis. X-ray diffraction (XRD) patterns were conducted on X. Pert Pro diffractometer using $\mathrm{Cu}$ $\mathrm{K} \alpha$ radiation $(\lambda=0.15418 \mathrm{~nm})$ at a scanning rate of $10^{\circ} / \mathrm{min}$.

2.4. Dye Solution Preparation. Methylene blue and Congo red were cationic and anionic dyes, respectively, and were used as model pollutants to study the adsorption properties of $\mathrm{TiO}_{2} @$ yeast-carbon microspheres. The structures of both dyes are shown in Figure 1. Stock $\mathrm{MB}$ and CR solutions $(1.0 \mathrm{~g} / \mathrm{L})$ were prepared by dissolving $1 \mathrm{~g}$ of $\mathrm{MB}$ or CR in $1 \mathrm{~L}$ of double distilled water, respectively. Experimental solutions of desired concentration were obtained by further dilution.

2.5. Analysis of Organic Dyes. The samples were separated from the solution at set intervals with centrifugation at $3000 \mathrm{rpm}$ for $5 \mathrm{~min}$ and were returned to the reaction system 
immediately after each analysis. The concentrations of $\mathrm{MB}$ and CR in the supernatant solution were determined using a double beam UV/visible spectrophotometer (UV-752, Shanghai) at $666.4 \mathrm{~nm}$ and $499.0 \mathrm{~nm}$, respectively. Calibration curve was found to be very reproducible and linear over the concentration range used in this work.

2.6. Batch Adsorption Experiments. Adsorption studies were carried by adding $0.25 \mathrm{~g} \mathrm{TiO}_{2} @ y e a s t-c a r b o n$ microspheres and $100 \mathrm{~mL} \mathrm{MB}$ or CR solution of certain concentration into a set of flasks followed by stirring in magnetic stirrers at room temperature without adjusting the solution $\mathrm{pH}$. The flasks were wrapped in aluminum foil to prevent photolysis. After desired adsorption time, $5 \mathrm{~mL}$ sample supernatant was taken out to analyze the residual concentration of MB or CR. In all sets of experiments, each test was conducted in duplicates, and the mean value was recorded. The amount of adsorbed dye per gram $\mathrm{TiO}_{2} @ y e a s t-c a r b o n$ hybrid microspheres at equilibrium $\left(q_{e}, \mathrm{mg} / \mathrm{g}\right)$ and at time $t\left(q_{t}, \mathrm{mg} / \mathrm{g}\right)$ was calculated by the following equation:

$$
\begin{aligned}
& q_{e}=\frac{\left(C_{0}-C_{e}\right) V}{m}, \\
& q_{t}=\frac{\left(C_{0}-C_{t}\right) V}{m},
\end{aligned}
$$

where $C_{0}, C_{e}$, and $C_{t}(\mathrm{mg} / \mathrm{g})$ are concentrations of dye at initial, equilibrium, and time $t$, respectively. $V$ (L) is the volume of the dye solution, and $m(\mathrm{~g})$ is the mass of adsorbent.

2.7. In Situ Regeneration of $\mathrm{TiO}_{2} @$ Yeast-Carbon Microspheres. In order to evaluate the reusability and renewability of the $\mathrm{TiO}_{2} @$ yeast-carbon, $\mathrm{MB}$ was chosen as the model pollutant. The procedure is as follows: an amount of $0.14 \mathrm{~g}$ of prepared $\mathrm{TiO}_{2} @ y e a s t-c a r b o n$ was suspended in a MB solution $(100 \mathrm{~mL})$ with an initial concentration of $2 \mathrm{mg} / \mathrm{L}$ in a beaker. The solution was magnetically stirred in dark for about $2.5 \mathrm{~h}$ to ensure the establishment of an adsorption-desorption equilibrium. Then, the mixed suspensions were irradiated under a UV lamp (Philips TL 8W/08F8T5/BLB; $0.0155 \mathrm{~m}$ bulb diameter, $0.26 \mathrm{~m}$ bulb length, and 1.2 W UVA output) located directly above the flasks at a distance of $6 \mathrm{~cm}$ from the surface of the solution. The aqueous samples were taken out at a regular interval time and analyzed until a second equilibrium was achieved, which meant that a cycle was over. At the end of each run, the dye-loaded $\mathrm{TiO}_{2} @ y e a s t-c a r b o n$ microspheres were collected by centrifugation, washed thoroughly, and dried to be reused in the next cycle. Another cycle of sorption-regeneration was repeated in the same manner as mentioned above. All of the experiments were performed in triplicate at room temperature. The removal rate $(\eta, \%)$ of $\mathrm{MB}$ was calculated by the following equation:

$$
\eta=\frac{\left(C_{0}-C_{e}\right)}{C_{0}} \times 100 \%
$$

\section{Results and Discussion}

3.1. Characterization. Figure 2(a) is the SEM images of yeastcarbon. It reveals that the yeast-carbon had smooth surface morphology and uniform size (length $=3.5 \pm 0.4 \mu \mathrm{m}$; width $=$ $2.3 \pm 0.5 \mu \mathrm{m})$. Figure 2(b) depicts an image of the $\mathrm{TiO}_{2} @ y e a s t$ which is the precursor of $\mathrm{TiO}_{2} @ y e a s t$-carbon. The size of $\mathrm{TiO}_{2} @$ yeast $($ length $=3.7 \pm 0.4 \mu \mathrm{m}$; width $=2.6 \pm 0.5 \mu \mathrm{m}$ ) increased compared with the yeast-carbon in Figure 2(a), which may be assigned to the attachment of $\mathrm{TiO}_{2}$ particles. Figure 2(c) presents an overall image of the $\mathrm{TiO}_{2}$ @yeastcarbon hybrid microspheres. The micrograph in Figure 2(c) indicates that the particles inherited the general shape and good dispersity of the precursor in Figure 2(b). Figures 2(d) and 2(e) expresses the $\mathrm{TiO}_{2} @ y e a s t$-carbon spheres in different magnifications. The $\mathrm{TiO}_{2} @ y e a s t$-carbon in Figure 2(d) exhibits a typical raspberry-like structure since the $\mathrm{TiO}_{2}$ nanoparticles were randomly decorated on the surface of carbon microspheres. Figure 2(f) displays the detailed information of the outer appearance of the $\mathrm{TiO}_{2} @ y e a s t$-carbon microspheres under a higher magnification. It can be clearly seen that the surfaces of the microspheres were coated with small $\mathrm{TiO}_{2}$ particles, whereas some residual bare areas still remained. These residual bare regions were of great benefit to the adsorption of dye molecules in aqueous solution.

Additionally, the unique raspberry-like structure of $\mathrm{TiO}_{2} @ y e a s t-c a r b o n$ is further confirmed from the EDS analysis. In the insert image in Figure 2(a), C, O, Zn, P, and Pt elements can be observed. $\mathrm{C}, \mathrm{O}$, and $\mathrm{P}$ result from the yeast cells, $\mathrm{Zn}$ element comes from the yeast cells activation agent $\mathrm{ZnCl}_{2}$, and $\mathrm{Pt}$ is assumed to be due to the metal spraying before SEM studies. C, O, P, and Ti elements are observed in the insert image in Figure 2(d). C, O, and P elements also derive from the yeast, and the Ti element detected indicates that $\mathrm{TiO}_{2}$ has been already successfully coated on the yeast carbon.

XRD patterns of $\mathrm{TiO}_{2}$, yeast, yeast-carbon, and $\mathrm{TiO}_{2} @$ yeast-carbon are shown in Figure 3. Diffraction peaks at around $20^{\circ}$ in Figures $3(\mathrm{a})$ and $3(\mathrm{~b})$ indicate the formation of amorphous species. Figure 3(c) illustrates an XRD pattern of $\mathrm{TiO}_{2}$ @yeast-carbon. The broad peak at $20^{\circ}$ is mainly caused by the amorphous structure of yeast-carbon. Moreover, the remaining diffraction peaks are in good agreement with $\mathrm{TiO}_{2}$ in Figure $3(\mathrm{~d})$ and no other diffraction peaks can be detected within the investigated range. Figure $3(\mathrm{~d})$ exhibits the XRD pattern of the original components of $\mathrm{TiO}_{2}$ nanoparticles $\left(\mathrm{P} 25 \mathrm{TiO}_{2}\right.$ : 78\% anatasetype $\mathrm{TiO}_{2}$ and $22 \%$ rutile-type $\mathrm{TiO}_{2}$ ). The observed sharper diffraction peaks at $25^{\circ}, 37.9^{\circ}, 48.2^{\circ}, 54.8^{\circ}$, and $63.0^{\circ}$ are consistent with diffraction peaks of anatase-type $\mathrm{TiO}_{2}$ (JCPDS. number: 21-1272) [22], and the other diffraction peaks centering at $69.0^{\circ}, 70.3^{\circ}$, and $75.0^{\circ}$ correspond well with the reflections of rutile-type $\mathrm{TiO}_{2}$ (JCPDS. number: 21-1276) [23].

3.2. Adsorption Capacity of $M B$ and $C R$ on $\mathrm{TiO}_{2} @$ YeastCarbon. Figure 4 describes the measured isotherms for $\mathrm{MB}$ and $\mathrm{CR}$ on the $\mathrm{TiO}_{2} @$ yeast-carbon samples at the same initial dye concentration. From Figure $4, Q_{t}$ for $\mathrm{MB}$ and $\mathrm{CR}$ 


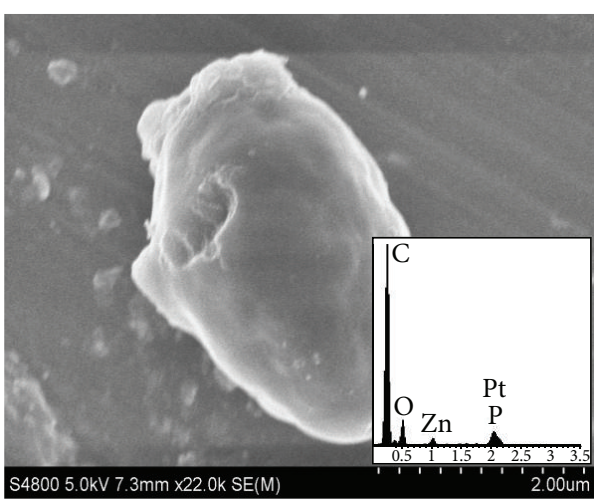

(a)

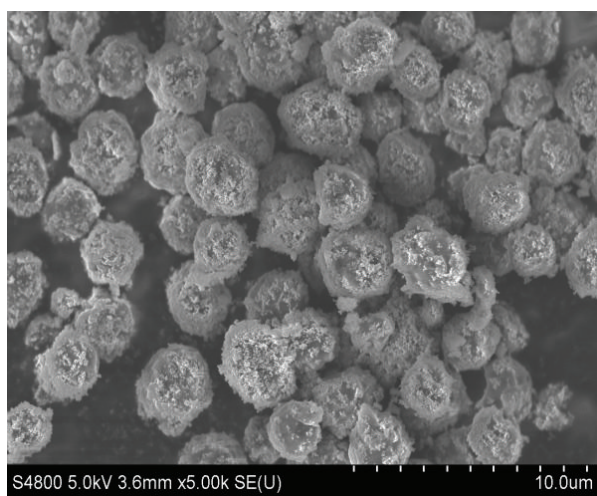

(c)

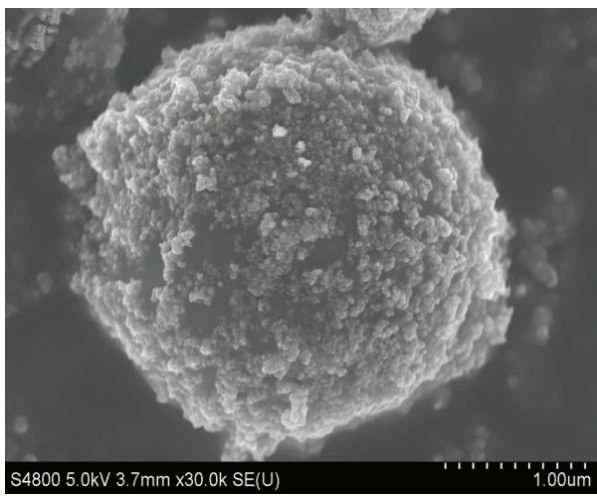

(e)

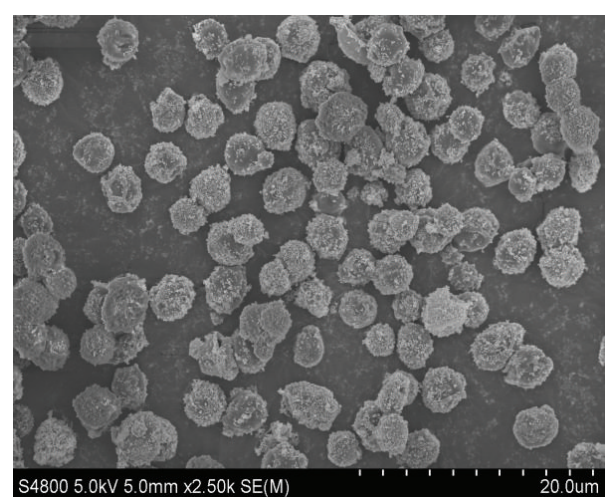

(b)

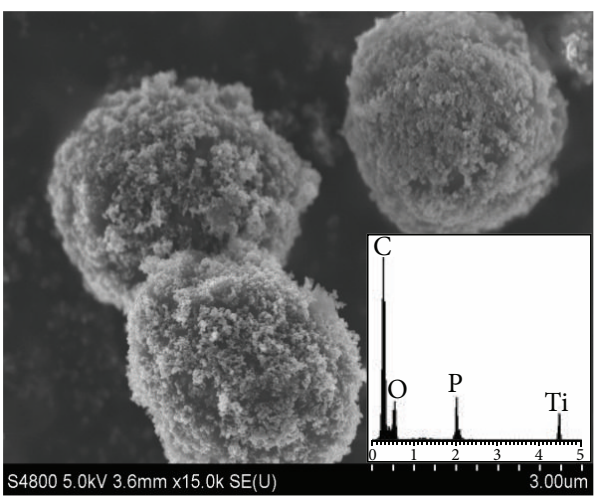

(d)

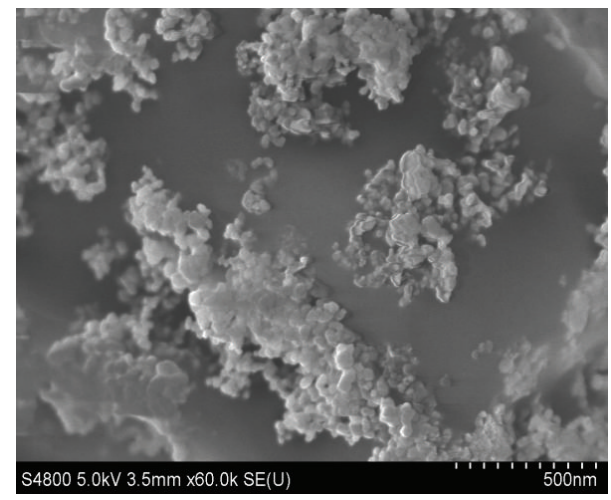

(f)

FIGURE 2: FE-SEM images of (a) the yeast-carbon, (b) general observation of the raspberry-like $\mathrm{TiO}_{2} @ y e a s t$ precursor, (c) the overall view of the raspberry-like $\mathrm{TiO}_{2} @ y$ east-carbon microspheres, (d-e) the selected raspberry-like $\mathrm{TiO}_{2} @ y$ east-carbon microspheres, and (f) typical raspberry-like $\mathrm{TiO}_{2} @$ yeast-carbon microspheres observed under high magnifications.

increased dramatically during the initial time. Then, $\mathrm{MB}$ and $\mathrm{CR}$ adsorption reached equilibrium at the time of about 80 and $130 \mathrm{~min}$, respectively, which was similar to observations of Hameed et al. [24]. As shown in Figure 4, two adsorption stages existed obviously: a very rapid initial adsorption over a few minutes, followed by a longer period of much slower uptake. The rapid uptake at the initial contact time could be ascribed to the fact that there were plenty of available adsorption active sites on the surface of $\mathrm{TiO}_{2} @ y$ yst-carbon, while the slow rate of dye adsorption was probably due to the repulsive forces between the dye molecules in the solution and on the surface of the $\mathrm{TiO}_{2} @ y e a s t-c a r b o n$ [25]. It can also be seen from Figure 4 that the adsorption capacity of cationic dye $\mathrm{MB}$ by $\mathrm{TiO}_{2} @$ @yeast-carbon was significantly higher than that of anionic dye CR, as manifested by the approximately 3 -fold higher adsorption capacity of the CR, which could be assigned to the negatively charged surface of the adsorbent [21, 26]. Moreover, because the CR possesses more polar atoms ( $\mathrm{N}$ and $\mathrm{S}$ ), the interaction between $\mathrm{CR}$ and $\mathrm{TiO}_{2} @ y$ yeast-carbon may be stronger than that between $\mathrm{MB}$ and $\mathrm{TiO}_{2} @$ yeast-carbon. This may induce a collapse in the pore structure of $\mathrm{TiO}_{2} @$ yeast-carbon and then create a 


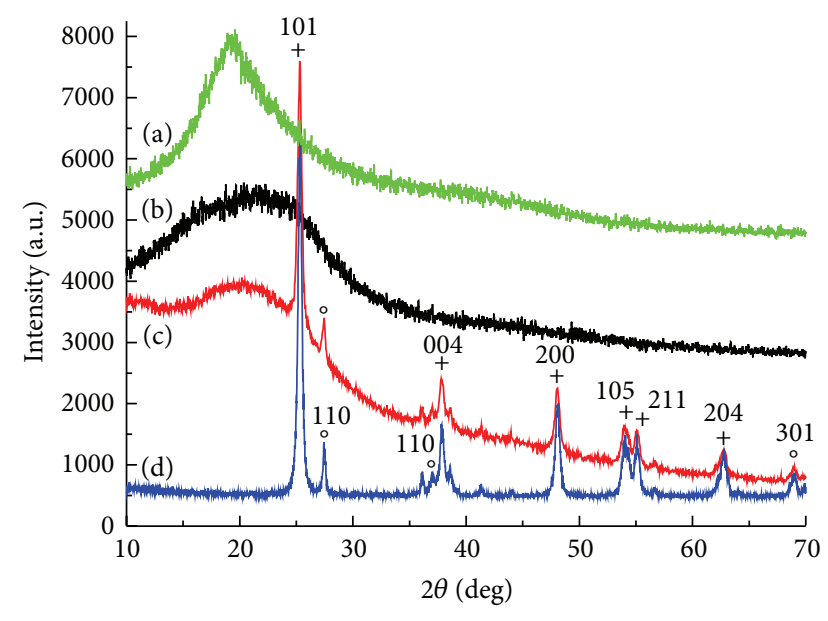

+ Anatase- $-\mathrm{TiO}_{2}$

- Rutile- $\mathrm{TiO}_{2}$

FIGURE 3: XRD patterns for (a) the premier yeast; (b) the prepared

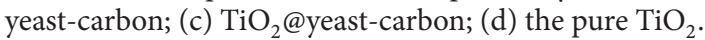

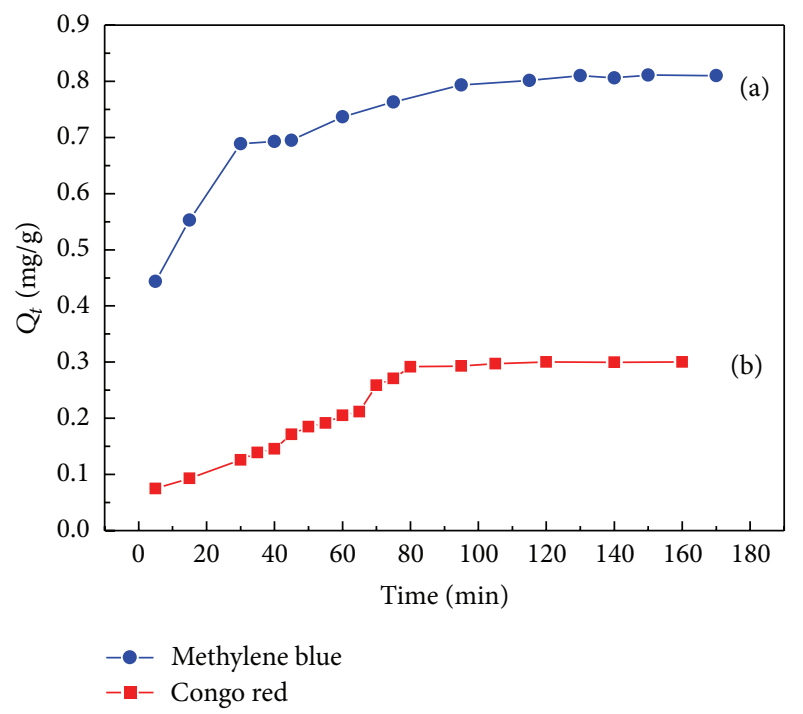

FIgURE 4: Adsorption isotherms for MB: (a) and CR: (b) on $\mathrm{TiO}_{2} @$ yeast-carbon.

sharp decrease in the adsorption capacity. It is noteworthy that the adsorption capacity of $\mathrm{MB}$ on $\mathrm{TiO}_{2} @ y e a s t-c a r b o n$ is similar to that of Basic Green 5 measured by Juang et al. [27]. According to the adsorption results above, it is experimentally demonstrated that $\mathrm{TiO}_{2} @ y e a s t$-carbon may be a good adsorbent for the removal of $\mathrm{MB}$ even if no chemical modification is taken.

The favorable removal of cationic MB in comparison with the anionic CR by TiO, @yeast-carbon adsorbent can be further verified by changing of initial dye concentration. Figure 5 illustrates the influence of dye concentration on adsorption capacity of $\mathrm{TiO}_{2} @ y e a s t-c a r b o n$ nanocomposite for $\mathrm{MB}$ and CR. As shown in Figure 5, the adsorption capacity for MB and CR augmented with the increase of dye concentration, which

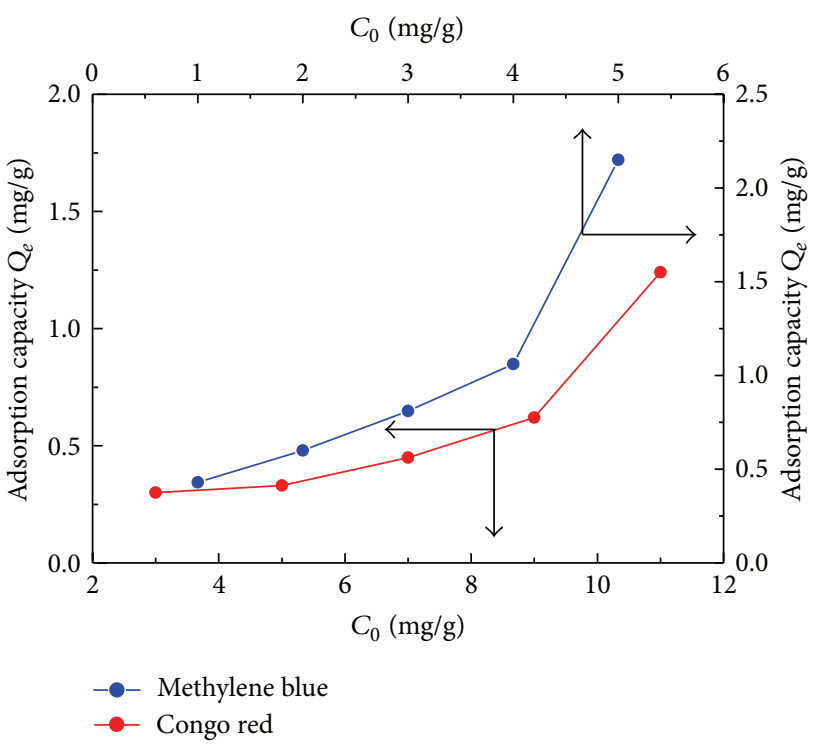

FIGURE 5: Influence of adsorbate concentration on adsorption capacity of $\mathrm{TiO}_{2} @ y e a s t-$ carbon nanocomposite for $\mathrm{MB}$ and $\mathrm{CR}$.

could be explained by the elevated concentration gradient between the bulk solution and the surface of the $\mathrm{TiO}_{2} @ y$ yeastcarbon [25]. As presented in Figure 5, the adsorption of $\mathrm{MB}$ on $\mathrm{TiO}_{2} @ y e a s t-c a r b o n$ showed higher capacity than $\mathrm{CR}$ within the investigated concentration. However, the adsorption capacity for $\mathrm{MB}$ or $\mathrm{CR}$ is sure to reach a constant if the dye concentration exceeds continuously because a certain amount of $\mathrm{TiO}_{2} @ y e a s t-c a r b o n$ could only provide limited active adsorption sites.

3.3. Adsorption Isotherms. Adsorption isotherm models are important to investigate how adsorbates interact with adsorbents [28] and are widely used to describe the adsorption progress [10]. Langmuir, Freundlich, Temkin, and KobleCorrigan isotherm models were used to fit the equilibrium data obtained from the study of $\mathrm{MB}$ and $\mathrm{CR}$ adsorption onto $\mathrm{TiO}_{2} @$ yeast-carbon at initial concentrations of $1.0 \sim 5.0 \mathrm{mg} / \mathrm{L}$ and $3.0 \sim 11.0 \mathrm{mg} / \mathrm{L}$, respectively.

Langmuir isotherm assumes monolayer adsorption onto a surface containing a finite number of adsorption sites of uniform strategies of adsorption with no transmigration of the adsorbate in the plane of surface $[10,29]$. The nonlinear Langmuir equation is given as

$$
Q_{e}=\frac{Q_{m} K_{L} C_{e}}{1+K_{L} C_{e}}
$$

where $Q_{e}$ is the amount of dye adsorbed per unit mass of the hybrid microspheres at equilibrium $(\mathrm{mg} / \mathrm{g}), C_{e}$ is the equilibrium concentration of the adsorbate $(\mathrm{mg} / \mathrm{L}), Q_{m}$ is the theoretical maximum adsorption capacity $(\mathrm{mg} / \mathrm{g})$, and $K_{L}$ is the Langmuir adsorption constant reflecting the tendency of adsorption (L/mg). 
To predict whether the adsorption process is favorable or unfavorable, equilibrium parameter $R_{L}$, a dimensionless constant separation factor, is defined by Weber and Chakravorti as the following equation [30]:

$$
R_{L}=\frac{1}{1+K_{L} C_{0, m}},
$$

where $C_{0, m}$ is the highest initial dye concentration $(\mathrm{mg} / \mathrm{L})$; the value of $R_{L}$ indicates the type of isotherm to be either favorable $\left(0<R_{L}<1\right)$, unfavorable $\left(R_{L}>1\right)$, irreversible $\left(R_{L}=0\right)$, or linear $\left(R_{L}=1\right)$.

The Freundlich model is an empirical theory based on adsorption on heterogeneous surface with nonuniform distribution of adsorption energy and affinities through a multilayer adsorption [31]. The nonlinear Freundlich equation is expressed as follows [32]:

$$
Q_{e}=K_{F} C_{e}^{1 / n},
$$

where $K_{F}$ is the Freundlich isotherm constant related to the sorption capacity and represents the strength of the adsorptive bond $\left(\mathrm{mg}^{-1} \mathrm{~g}^{-1}\left(\mathrm{~L} \cdot \mathrm{mg}^{-1}\right)^{1 / n}\right)$. The constant $1 / n$ gives an indication of how favorable the adsorption process is, and a value between 0.1 and 1.0 represents a favorable adsorption [33].

Moreover, Temkin isotherm takes the adsorbate-adsorbent interactions into account based on the assumptions that the heat of adsorption of all the molecules in the layer decreases linearly with coverage due to adsorbent-adsorbate interactions and that the adsorption is characterized by a uniform distribution of binding energies, up to some maximum binding energy $[34,35]$. The Temkin isotherm has generally been applied as

$$
Q_{e}=A \cdot \ln \left(B \cdot C_{e}\right),
$$

where $A=R T / b$ and $b$ is $\mathrm{J} / \mathrm{mol}, T(\mathrm{~K})$ is the absolute temperature, $R(8.314 \mathrm{~J} / \mathrm{mol} \cdot \mathrm{K})$ is the universal gas constant, and $B(\mathrm{~L} / \mathrm{mol})$ is the equilibrium binding constant corresponding to the maximum binding energy, respectively.

Koble-Corrigen (K-C) isotherm model is an empirical three-parameter model which combines both Langmuir and Freundlich isotherm models for representing equilibrium adsorption data and is given by (7) as follows [36]:

$$
Q_{e}=\frac{A_{\mathrm{KC}} \cdot C_{e}^{\beta}}{1+B_{\mathrm{KC}} C_{e}^{\beta}},
$$

where $A_{\mathrm{KC}}, B_{\mathrm{KC}}$, and $\beta$ are Koble-Corrigen isotherm constants. When $\beta=1$, the equation reduces to Langmuir equation; if $B_{\mathrm{KC}} \cdot C_{e}^{\beta} \ll 1$, the equation becomes Freundlich equation. If $B_{\mathrm{KC}} \cdot C_{e}^{\beta} \gg 1$, the adsorbate quantity per unit weight of adsorbent at equilibrium remains to be a constant of $A_{\mathrm{KC}} / B_{\mathrm{KC}}$ [37].

A comparison of the adsorption experimental isotherms of $\mathrm{MB}$ onto the $\mathrm{TiO}_{2} @ y e a s t-c a r b o n$ and theoretical plots of the Langmuir, Freundlich, Temkin, and Koble-Corrigan isotherm models was shown in Figure 6. Correlation coefficients and constants of the models were given in Table 1.

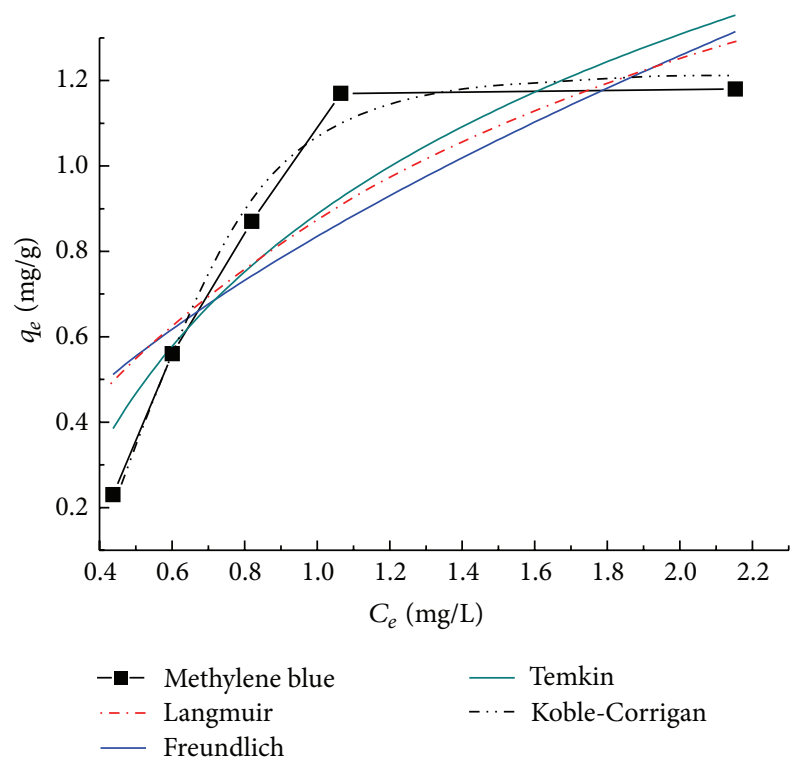

FIgURE 6: Comparison of Langmuir, Freundlich, Temkin, and Koble-Corrigan isotherm models for $\mathrm{MB}$ adsorption onto $\mathrm{TiO}_{2} @$ yeast-carbon composites (adsorbent $=0.014 \mathrm{~g}$; solution volume $=100 \mathrm{~mL} ; \mathrm{pH}=6$; contact time $=1.5 \mathrm{~h}$; temperature $=298 \mathrm{~K}$; and concentration of $\mathrm{MB}=1.0,2.0,3.0,4.0$, and $5.0 \mathrm{mg} / \mathrm{L}$, resp.).

TABLE 1: Isotherm constants for the adsorption of MB and CR onto $\mathrm{TiO}_{2} @$ yeast-carbon.

\begin{tabular}{lccc}
\hline $\begin{array}{l}\text { Adsorption isotherm } \\
\text { models }\end{array}$ & Constants & $\mathrm{MB}$ & $\mathrm{CR}$ \\
\hline \multirow{4}{*}{ Langmuir isotherm } & $Q_{m}(\mathrm{mg} / \mathrm{g})$ & 2.20 & 1.62 \\
& $K_{L}(\mathrm{l} / \mathrm{mg})$ & 0.65 & 0.57 \\
& $R^{2}$ & 0.6745 & 0.9128 \\
& $R^{L}$ & 0.2346 & 0.2597 \\
\hline \multirow{3}{*}{ Freundlich isotherm } & $K_{F}\left[(\mathrm{mg} / \mathrm{g})\left(\mathrm{mg}^{-1}\right)^{1 / n}\right]$ & 0.630 & 0.655 \\
& $R^{2}$ & 0.840 & 0.033 \\
Temkin isotherm & $A$ & 0.607 & 0.9920 \\
\hline \multirow{3}{*}{ Koble-Corrigan } & $B$ & 4.314 & 0.500 \\
isotherm & $R^{2}$ & 0.7517 & 0.9134 \\
\hline & $A_{\mathrm{KC}}$ & 8.63 & 0.03 \\
& $B_{\mathrm{KC}}$ & 7.08 & 5.22 \\
& $\beta$ & 4.20 & 1.54 \\
& $R^{2}$ & 0.9745 & 0.9883 \\
\hline
\end{tabular}

As can be seen from Figure 6, Koble-Corrigan isotherm plot was very close to the experimental data plot. Besides, it was observed in Table 1 that the value of $R^{2}$ of Koble-Corrigan model $\left(R^{2}>0.97\right)$ was higher than those of Temkin, Langmuir, and Freundlich isotherm models, showing that KobleCorrigan model was most suitable for the $\mathrm{MB}$ adsorption than the other models. This indicated that a combination of heterogeneous and homogeneous uptakes occurred in $\mathrm{MB}$ uptake by the synthesized $\mathrm{TiO}_{2} @ y e a s t-c a r b o n$. Meanwhile, 
TABLE 2: Isotherm models for adsorption of $\mathrm{MB}$ and $\mathrm{CR}$ on various adsorbents.

\begin{tabular}{|c|c|c|c|}
\hline Adsorbent & Dyes & Adsorption isotherm & Reference \\
\hline Activated carbon/cobalt ferrite/alginate & $\mathrm{MB}$ & Langmuir, Freundlich & Ai et al. [40] \\
\hline Bamboo-based activated carbon & MB & Langmuir & Hameed et al. [24] \\
\hline $\mathrm{TiO}_{2} @$ yeast & $\mathrm{MB}$ & Langmuir & Chen and Bai [33] \\
\hline Graphene & $\mathrm{MB}$ & Langmuir & Liu et al. [41] \\
\hline Perlite & $\mathrm{MB}$ & Langmuir & Doğan et al. [42] \\
\hline Garlic peel & $\mathrm{MB}$ & Freundlich & Hameed and Ahmad [43] \\
\hline $\mathrm{TiO}_{2} @$ yeast-carbon & $\mathrm{MB}$ & Koble-Corrigan & This study \\
\hline Bagasse fly ash and activated carbon & CR & Redlich-Peterson & Mall et al. [34] \\
\hline Kaolin & CR & Langmuir & Vimonses et al. [2] \\
\hline Bentonite zeolite & CR & Freundlich & Vimonses et al. [2] \\
\hline Activated carbon prepared from coir pith & CR & Langmuir, Freundlich & Namasivayam and Kavitha [44] \\
\hline Chitosan/montmorillonite nanocomposite & $\mathrm{CR}$ & Langmuir & L. Wang and A. Wang [45] \\
\hline $\mathrm{TiO}_{2} @$ yeast-carbon & $\mathrm{CR}$ & Freundlich, Koble-Corrigan & This study \\
\hline
\end{tabular}

comparing the coefficients of determination of the Langmuir and Freundlich models, we could infer that homogeneous uptake was the main mechanism of the $\mathrm{MB}$ adsorption process [38]. Moreover, the value of $R_{L}$ from the Langmuir isotherm was between 0 and 1 , the Freundlich constant $1 / n$ was smaller than 1 , and the value $\beta$ in Koble-Corrigan model is over 1 , indicating that the adsorption of $\mathrm{MB}$ onto $\mathrm{TiO}_{2} @ y e a s t-c a r b o n$ was a favorable adsorption process.

Figure 7 typically showed the adsorption isotherms of CR onto the $\mathrm{TiO}_{2} @ y e a s t$-carbon. The parameters of the isotherm equations were summarized in Table 1. It was shown in Figure 7 that both Koble-Corrigan and Freundlich models are suitable for CR adsorption process. From Figure 7, the low deviation between the calculated behavior and experimental plot had been observed. This fitting result can be explained by the presence of competition between adsorbate molecules for the adsorption sites on the surface [36]. The higher value of $R^{2}$ in Table 1 from Freundlich model than Koble-Corrigan model implied that Freundlich model fitted the most exactly. In contrast, the $R_{L}$ value obtained from the Langmuir model, the Freundlich constant $(1 / n)$, and the value $\beta$ from KobleCorrigan model exhibited the same tendency as those for MB adsorption above, representing that the adsorption of CR on the $\mathrm{TiO}_{2} @ y e a s t-c a r b o n$ was favorable.

The above analyses showed that the Koble-Corrigan model yields a better fit of MB than the other models. CR adsorption on the $\mathrm{TiO}_{2} @ y e a s t-c a r b o n$ microspheres conforms well to Freundlich and Koble-Corrigan models. Namely, the Koble-Corrigan model fitted both MB and CR adsorption well. In addition, constants of $A_{\mathrm{KC}}$ and $B_{\mathrm{KC}}$ from Koble-Corrigan model are indicators of adsorption capacity and affinity of the adsorbent [36]. The values of KolbeCorrigan constant $A_{\mathrm{KC}}$ were 8.63 and 0.03 and those of $B_{\mathrm{KC}}$ were 7.08 and 5.22 for $\mathrm{MB}$ and $\mathrm{CR}$, respectively. The greater $A_{\mathrm{KC}}$ and $B_{\mathrm{KC}}$ values for $\mathrm{MB}$ indicated higher $\mathrm{MB}$ adsorption capacity, affinity, and intensity compared to CR adsorption onto $\mathrm{TiO}_{2} @ y e a s t$-carbon microspheres. This phenomenon was in accordance with the result illustrated in Figure 4, which may be attributed to the different active functional groups in $\mathrm{MB}$ and $\mathrm{CR}$ molecules [39], revealing that the

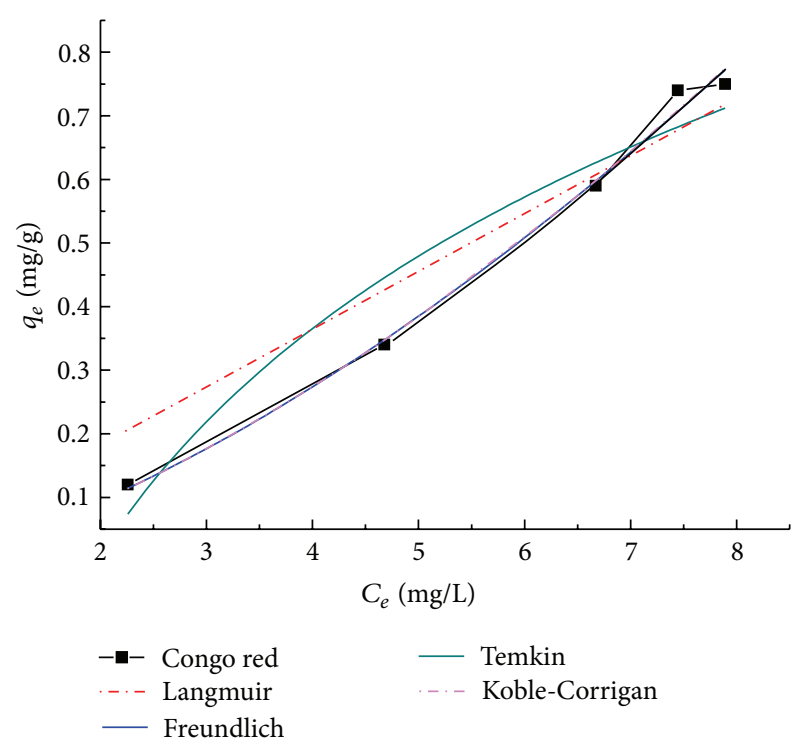

Figure 7: Comparison of Langmuir, Freundlich, Temkin, and K$\mathrm{C}$ isotherm models for CR adsorption onto $\mathrm{TiO}_{2} @$ yeast-carbon composites (adsorbent $=0.014 \mathrm{~g}$; solution volume $=100 \mathrm{~mL}$; $\mathrm{pH}=$ 6 ; contact time $=1.5 \mathrm{~h}$; temperature $=298 \mathrm{~K}$; and concentration of $\mathrm{CR}=3.0,5.0,7.0,9.0$, and $11.0 \mathrm{mg} / \mathrm{L}$, resp.).

$\mathrm{TiO}_{2} @$ yeast-carbon microspheres can be served as a promising adsorptive material for $\mathrm{MB}$.

Since adsorption isotherm is basically important to describe how adsorbates interact with adsorbents, some researchers had also investigated the best fitted isotherm models for the adsorption of $\mathrm{MB}$ and $\mathrm{CR}$ onto several adsorbents in aqueous solutions [2, 24, 33, 34, 40-45]. The results were listed in Table 2, and the $\mathrm{TiO}_{2} @ y e a s t$-carbon studied in this work represented different adsorption behaviors.

3.4. Adsorption Kinetics. To investigate the adsorption mechanism, such as mass transfer and chemical reaction, the $\mathrm{MB}$ and CR adsorption data were analyzed using the pseudo-firstorder and pseudo-second-order models, respectively. The 


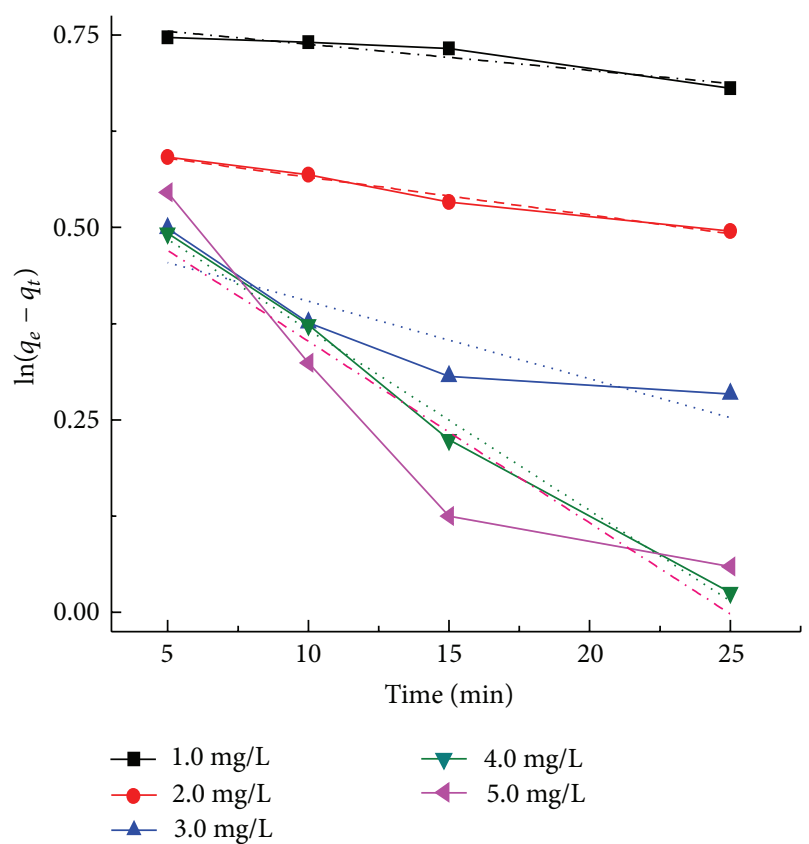

(a)

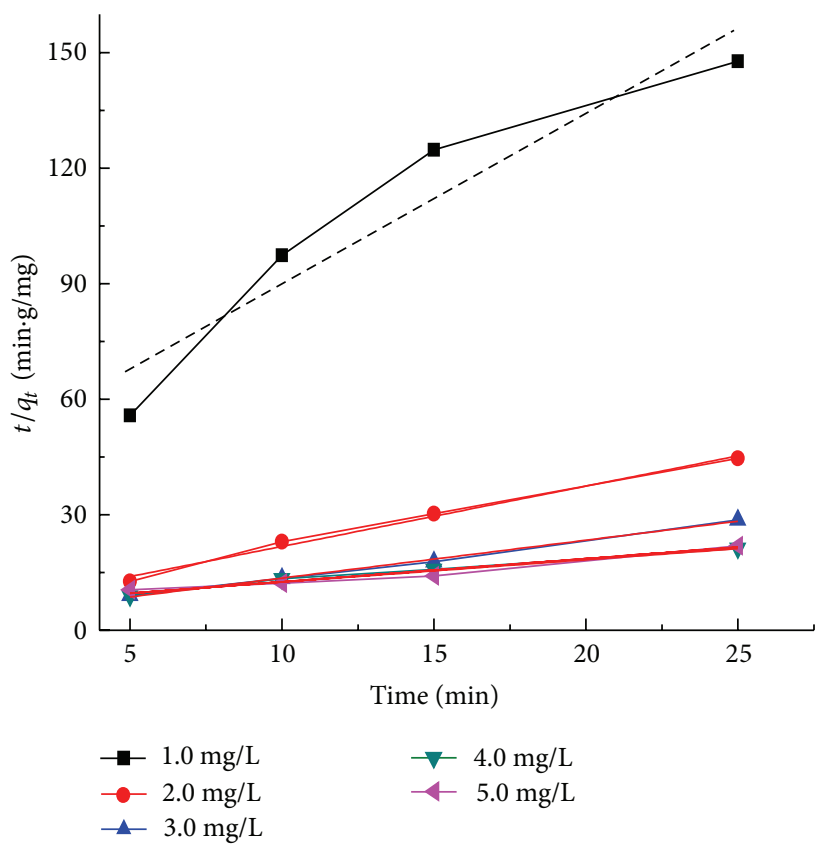

(b)

Figure 8: Pseudo-first-order (a) and pseudo-second-order (b) adsorption kinetics for adsorption of $\mathrm{MB}_{\text {onto TiO}} @$ @yeast-carbon at different initial concentrations $\left(\mathrm{TiO}_{2} @\right.$ yeast-carbon dosage $=0.14 \mathrm{~g} / \mathrm{L} ; \mathrm{pH}=6.0$; temperature $=298 \mathrm{~K}$; and concentration of $\mathrm{MB}=1.0,2.0$, 3.0, 4.0, and $5.0 \mathrm{mg} / \mathrm{L}, \mathrm{resp}$.$) .$

pseudo-first-order kinetic model was described by Lagergren and the pseudo-second-order kinetic model was based on the assumption that the rate limiting step of the adsorption process was chemical sorption [25]. The pseudo-first-order equation can be expressed as [46]

$$
\ln \left(Q_{e}-Q_{t}\right)=\ln Q_{e}-k_{1} \cdot t,
$$

where $Q_{e}(\mathrm{mg} / \mathrm{g})$ and $Q_{t}(\mathrm{mg} / \mathrm{g})$ are the amounts of dye adsorbed onto the composites at equilibrium and at time $t$, respectively. The rate constant $k_{1}\left(\mathrm{~min}^{-1}\right)$ of the pseudo-firstorder model was calculated from the plots of $\ln \left(Q_{e}-Q_{t}\right)$ versus $t$.

The pseudo-second-order equation can be described in the following equation [28]:

$$
\frac{t}{Q_{t}}=\frac{1}{\left(k_{2} \cdot Q_{e}^{2}\right)}+\frac{t}{Q_{e}}
$$

where $k_{2}\left(\mathrm{~g} \cdot \mathrm{mg}^{-1} \cdot \mathrm{min}^{-1}\right)$ is the adsorption rate constant of the pseudo-second-order equation and can be obtained from the linear plots of $t / Q_{t}$ against $t$.

Besides, the applicability of both kinetic models was tested through the sum of error squares (SSE, \%), which was given as follows [47]:

$$
\operatorname{SSE}(\%)=\sqrt{\frac{\sum\left(Q_{e, \exp }-Q_{e, \mathrm{cal}}\right)^{2}}{N}},
$$

where $N$ is the number of data points. The higher the correlation coefficient $\left(R^{2}\right)$ and the lower the values of SSE, the better the goodness of fit will be. Table 3 also listed the calculated SSE results for MB and CR adsorption onto $\mathrm{TiO}_{2} @ y e a s t-c a r b o n$ at different initial concentrations.

Figure 8 exhibits the plots of the pseudo-first-order and pseudo-second-order kinetics of MB adsorption on $\mathrm{TiO}_{2} @ y e a s t-c a r b o n$ at different initial concentrations. The adsorption rate constants, correlation coefficient, and SSE values were calculated and summarized in Table 2. It was observed from Table 2 that the experimental $Q_{e}$ values $\left(Q_{e, \exp }\right)$ did not agree with the calculated ones $\left(Q_{e, \text { cal }}\right)$ although the correlation coefficient values for the pseudofirst-order at some concentrations were higher than 0.85 . As a result, the sorption of $\mathrm{MB}$ on the $\mathrm{TiO}_{2} @ y e a s t-c a r b o n$ did not follow pseudo-first-order in all cases. It was also obvious that the correlation coefficient $R^{2}$ was found to range from 0.936 to 0.994 for the pseudo-second-order kinetic model, which were higher than those for the pseudo-second-order model, and the experimental $Q_{e}$ values $\left(Q_{e, \exp }\right)$ were closer with the theoretical calculated values $\left(Q_{e, \text { cal }}\right)$ compared to the pseudo-first-order model. Furthermore, SSE values for the pseudo-second-order model were lower than those for the pseudo-second-order model. All the illustrations mentioned above indicated that the adsorption of $\mathrm{MB}$ onto $\mathrm{TiO}_{2} @ y e a s t-$ carbon followed the pseudo-second-order kinetic model, and the chemical sorption might be involved in the adsorption process. Moreover, the rate constant $\left(k_{2}\right)$ decreased with the increase of the initial $\mathrm{MB}$ concentrations, which was due to the striking hindrance of higher concentrations of MB [40].

Figure 9 presents the plots of the pseudo-first-order and pseudo-second-order kinetics of CR adsorption on 
TABLE 3: Kinetic adsorption parameters of different initial concentration of MB and CR.

\begin{tabular}{|c|c|c|c|c|c|c|c|c|c|}
\hline \multirow{2}{*}{$C_{0}(\mathrm{mg} / \mathrm{L})$} & \multirow{2}{*}{$Q_{e, \exp }(\mathrm{mg} / \mathrm{g})$} & \multicolumn{4}{|c|}{ Pseudo-first-order } & \multicolumn{4}{|c|}{ Pseudo-second-order } \\
\hline & & $k_{1}\left(\min ^{-1}\right)$ & $Q_{e, \text { cal }}(\mathrm{mg} / \mathrm{g})$ & $R^{2}$ & SSE (\%) & $k_{2}(\mathrm{~g} / \mathrm{mg} \cdot \mathrm{min})$ & $Q_{e, \text { cal }}(\mathrm{mg} / \mathrm{g})$ & $R^{2}$ & SSE (\%) \\
\hline \multicolumn{10}{|c|}{ MB } \\
\hline 1.0 & 0.43 & $3.4 \times 10^{-3}$ & 2.16 & 0.868 & 0.87 & 0.426 & 0.39 & 0.961 & 0.10 \\
\hline 2.0 & 0.60 & $4.9 \times 10^{-3}$ & 1.65 & 0.912 & 1.01 & 0.404 & 0.63 & 0.989 & 0.08 \\
\hline 3.0 & 0.81 & $1.0 \times 10^{-2}$ & 1.82 & 0.683 & 0.42 & 0.260 & 1.01 & 0.994 & 0.02 \\
\hline 4.0 & 1.06 & $2.4 \times 10^{-2}$ & 1.79 & 0.953 & 0.38 & 0.055 & 1.16 & 0.976 & 0.24 \\
\hline 5.0 & 2.15 & $2.0 \times 10^{-2}$ & 1.84 & 0.767 & 0.18 & 0.049 & 2.14 & 0.936 & 0.32 \\
\hline \multicolumn{10}{|c|}{$\mathrm{CR}$} \\
\hline 3.0 & 0.29 & $9.6 \times 10^{-2}$ & 1.67 & 0.960 & 0.69 & 0.270 & 0.30 & 0.981 & 0.04 \\
\hline 9.0 & 0.62 & $8.5 \times 10^{-2}$ & 1.25 & 0.903 & 0.32 & 0.052 & 0.64 & 0.989 & 0.11 \\
\hline 11.0 & 1.24 & $11.0 \times 10^{-2}$ & 3.75 & 0.941 & 1.25 & 0.040 & 1.33 & 0.994 & 0.01 \\
\hline
\end{tabular}

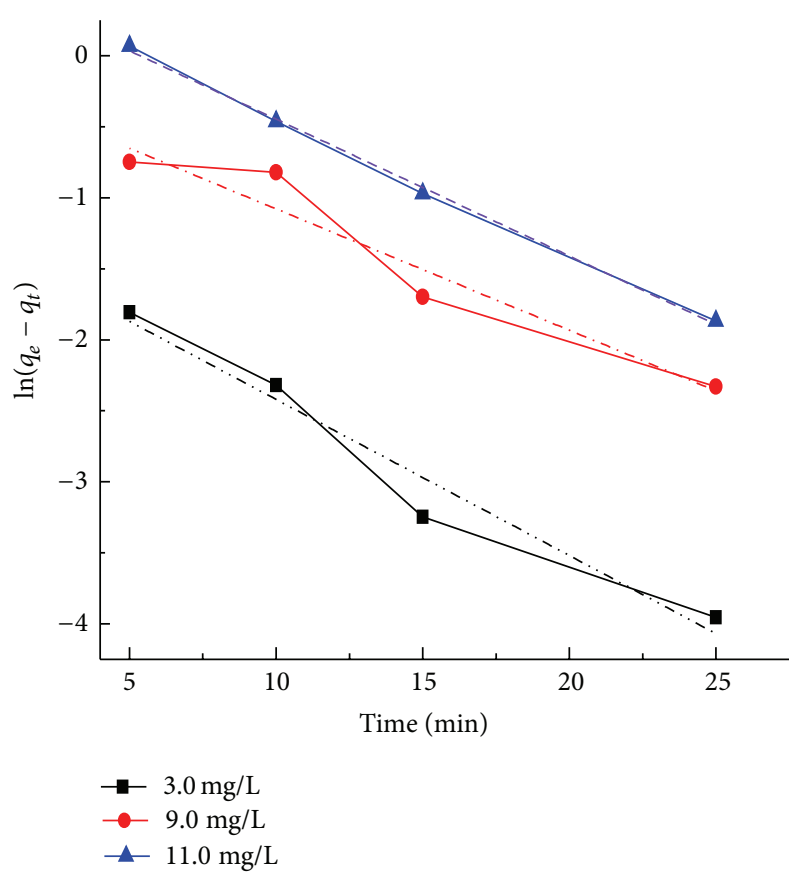

(a)

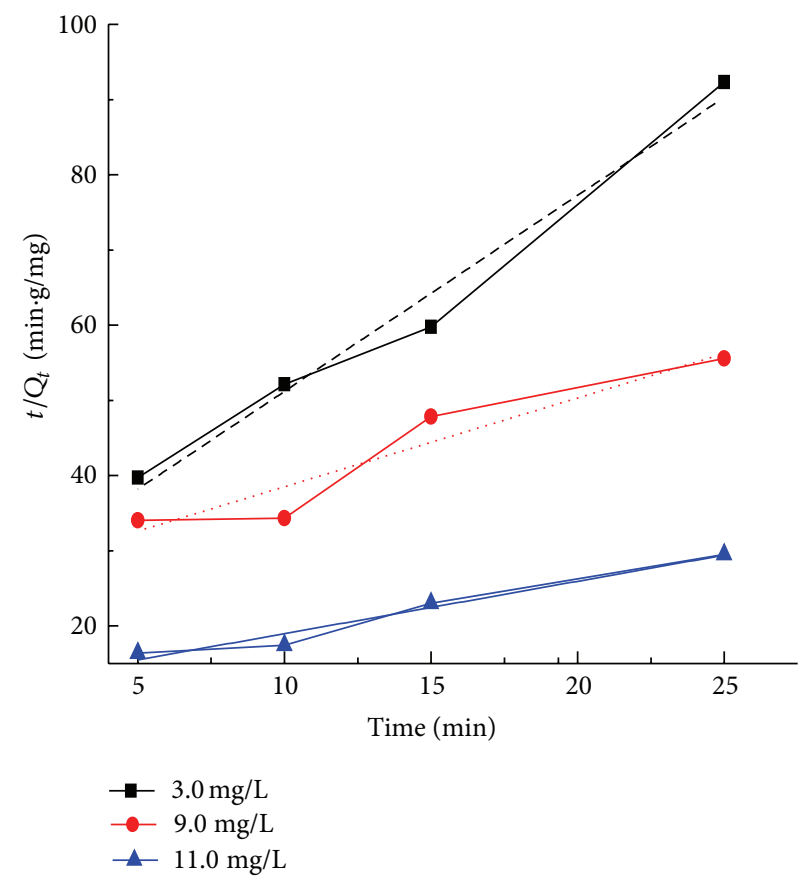

(b)

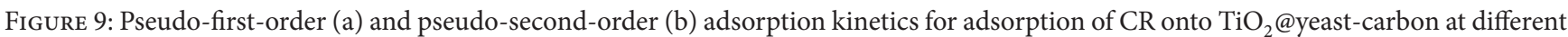
initial concentrations $\left(\mathrm{TiO}_{2} @\right.$ yeast-carbon dosage $=0.14 \mathrm{~g} / \mathrm{L} ; \mathrm{pH}=6.0$; temperature $=298 \mathrm{~K}$; and concentration of $\mathrm{MB}=3.0,9.0$, and 11.0 mg $/ \mathrm{L}$, resp.).

$\mathrm{TiO}_{2} @ y e a s t-c a r b o n$ at different initial concentrations. The adsorption rate constants, correlation coefficient, and SSE values are also given in Table 3. The results presented an ideal fit to the pseudo-second-order kinetics for all concentrations with the higher correlation coefficient $\left(R^{2}>0.98\right)$ and lower SSE values. A good agreement with this model was confirmed by the similar values of calculated adsorption capacity at equilibrium $\left(Q_{e, \text { cal }}\right)$ and experimental ones $\left(Q_{e, \exp }\right)$ for all concentrations. The best fit to the pseudo-secondorder kinetics model indicates that the adsorption mechanism depends on the adsorbate and adsorbent, and the rate controlling step might be chemical sorption involving valence forces through exchange or sharing of electrons [2]. The rate constant $\left(k_{2}\right)$ also decreased with the increase of the initial $\mathrm{CR}$ concentrations, owing to that the higher probability of collisions among CR molecules would decrease the sorption rate [28]. Similar kinetic results have also been reported for the CR adsorption onto bagasse fly ash [34], activated carbon from coir [44], and chitosan/montmorillonite [45].

\subsection{Regeneration of Dye Loaded TiO $@$ @Yeast-Carbon Micro-} spheres. No matter if adsorption is carried out in statical or dynamical forms, it will gradually reach equilibrium if more contaminated water was treated or more adsorption cycles were conducted without regeneration [48]. So the removal of 


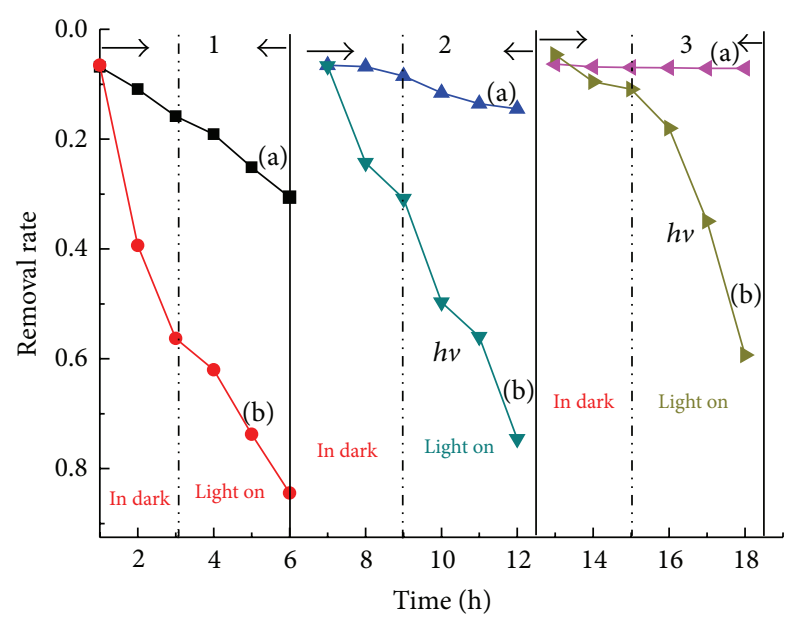

(a): Yeast-carbon

(b): TiO2@yeast-carbon

FIGURE 10: The circulation experiment of $\mathrm{TiO}_{2} @ y e a s t-c a r b o n$ composite microspheres.

adsorbed pollutants and the regeneration study of saturated composite were completely necessary. Hence, experiments were performed to evaluate the lifetime and reusing efficiency of prepared composite in removing MB (Figure 10).

For the dark adsorption section in the first cycle, near absorption-desorption equilibrium was established during the $3.0 \mathrm{~h}$ dark phase before the irradiation of the dyes solutions. It can also be seen from Figure 10 that strengthening trend occurs for the adsorption capacities of $\mathrm{TiO}_{2}$ @yeastcarbon microsphere when $\mathrm{TiO}_{2}$ nanoparticles were attached onto the yeast-carbon. This enhanced effect of absorption might be ascribed to the integration of yeast-carbon and $\mathrm{TiO}_{2}$ nanoparticles, which creates more adsorption sites for $\mathrm{MB}$. The dark adsorption results show that $\mathrm{TiO}_{2} @ y e a s t-$ carbon microsphere have faster adsorption kinetics due to their larger vacant surface area compared to the naked yeastcarbon. This phenomenon can be further affirmed by the pseudo-first-order kinetic data in Table 4. As can be seen, the kinetic rate constant in dark $\left(k_{\text {dark }}\right)$ for $\mathrm{TiO}_{2} @ y e a s t-$ carbon is $5.5 \times 10^{-3}$, which is almost 4.2 times of that for the yeast-carbon. The higher $k_{\text {dark }}$ gave clear evidence that $\mathrm{TiO}_{2} @ y e a s t-c a r b o n$ exhibited higher adsorption rate than yeast-carbon. Thereafter, the experiments for the removal of $\mathrm{MB}$ compound from aqueous solution were continued for about $3 \mathrm{~h}$ under UV light irradiation. Figure 10 shows that in the first cycle approximately $30 \%$ of $\mathrm{MB}$ was removed from the aqueous solution by adsorption on the naked yeastcarbon. In the presence of the raspberry-like $\mathrm{TiO}_{2} @ y$ yeastcarbon microspheres and under UV irradiation, nearly 85\% of MB molecule disappearance was accomplished.

These results suggest that the prepared $\mathrm{TiO}_{2} @ y e a s t-$ carbon composites are effective for the removal of $\mathrm{MB}$ from aqueous solutions. The integration of adsorption by the yeast-carbon with photocatalysis by the $\mathrm{TiO}_{2}$ nanoparticles attached on the yeast-carbon surface showed a combined function in the removal of the MB molecule. Specifically, yeast-carbon can increase the photodegradation rate by progressively allowing an increased concentration of $\mathrm{MB}$ to come in contact with the $\mathrm{TiO}_{2}$ nanoparticles through means of adsorption. $\mathrm{TiO}_{2}$ nanoparticles on the surface of yeastcarbon can be activated to generate hydroxyl free radicals, which can decompose most of the MB molecules and keep the adsorption sites unsaturated. In return, the simultaneous adsorption of the MB molecules onto the renewed areas of the yeast-carbon provides a continuous supply of substrate to the $\mathrm{TiO}_{2}$ nanoparticles [49]. Thus, the adsorption performance of the yeast-carbon and the photocatalytic property of the attached $\mathrm{TiO}_{2}$ have been integrated as a novel property for the raspberry-like $\mathrm{TiO}_{2} @ y e a s t-c a r b o n$ composites.

It was also observed in Figure 10 that, after three times reuses, the $\mathrm{MB}$ removal by yeast-carbon apparently dropped from $30.6 \%$ to $7.0 \%$. It could be attributed to the fact that the removal of $\mathrm{MB}$ in aqueous solution by yeast-carbon mostly relied on adsorption, which fully depended on the absorption sites. Hereby, the bare active sites on yeast-carbon were covered by MB molecules adsorbed in the last cycle, which gave explanation for the rapid loss of MB removal. However, the $\mathrm{TiO}_{2} @ y e a s t$-carbon still achieved desired removal efficiency for $\mathrm{MB}$ with slight decrease from $84.4 \%$ to $59.3 \%$ even though it had been reused for three times; that is, after 3 successive cycles under UV light irradiation, the removal rate of $\mathrm{MB}$ by $\mathrm{TiO}_{2}$ @yeast-carbon was still 70\% of that for the first cycling run. These phenomena give evidence that $\mathrm{TiO}_{2} @ y e a s t-c a r b o n$ nanocomposites exhibited excellent photocatalytic stability and regeneration efficiency.

The outstanding regeneration ability of $\mathrm{TiO}_{2} @ y e a s t-$ carbon in comparison with the yeast-carbon could be further affirmed by contrasting the pseudo-first-order kinetic rate constants $k_{\text {dark }}$ (in dark) and $k_{\text {light }}$ (light on) in Table 4. As can be seen, the $k_{\text {dark }}$ for $\mathrm{TiO}_{2} @ y$ yeast-carbon during three cycle times are $5.5 \times 10^{-3}, 4.2 \times 10^{-3}$, and $9.0 \times 10^{-3}$, respectively, which were almost $4.2,15.0$, and 10.1 times those for the yeast-carbon. The higher $k_{\text {dark }}$ means that $\mathrm{TiO}_{2} @$ yeast-carbon regenerated by UV light illumination exhibited higher adsorption rate than yeast-carbon. Besides, irradiation of yeast-carbon after dark adsorption equilibrium had resulted in smaller $k_{\text {light }}\left(1.22 \times 10^{-3}, 5.7 \times 10^{-4}\right.$, and $1.7 \times 10^{-5}$ ) compared to $\mathrm{TiO}_{2} @$ yeast-carbon under UV light, showing that the attachment of $\mathrm{TiO}_{2}$ nanoparticles on the surface of yeast-carbon had a great significant influence on the removal rate of $\mathrm{MB}$ and implied that in situ regeneration of the MB-loaded TiO $@$ @yeast-carbon had already occurred.

3.6. In Situ Regenerating Mechanism for TiO $@$ @east-Carbon. Based on the results above, a synergistic effect might be one possible mechanism for in situ regenerating dye-loaded $\mathrm{TiO}_{2} @ y e a s t-c a r b o n$. The synergistic effect works by integrating the adsorption of the yeast-carbon with the photocatalysis of the $\mathrm{TiO}_{2}$ nanoparticles attached on the yeast-carbon surface. More specifically, based on the bare areas on the surface of yeast-carbon and $\mathrm{TiO}_{2}$, dye molecules were adsorbed onto the $\mathrm{TiO}_{2} @ y e a s t-c a r b o n$ through means of adsorption. Then, the adsorption sites are keeping unsaturated by illuminating the whole system. Because the irradiation of $\mathrm{TiO}_{2}$ particles 
TABLE 4: Kinetic constant (g/mg.min) $k_{\text {dark }}$ (in dark), $k_{\text {light }}$ (light on), and Adj. $R$-Square $R^{2}$ for removing MB.

\begin{tabular}{lcccccc}
\hline & \multicolumn{2}{c}{ Cycle 1 } & \multicolumn{2}{c}{ Cycle 2 } & \multicolumn{2}{c}{ Cycle 3 } \\
& Yeast-carbon & $\mathrm{TiO}_{2} @ y$ yeast-carbon & Yeast-carbon & $\mathrm{TiO}_{2} @ y$ yeast-carbon & yeast-carbon & TiO $@$ @yeast-carbon \\
\hline$k_{\text {dark }}$ & $1.3 \times 10^{-3}$ & $5.5 \times 10^{-3}$ & $2.8 \times 10^{-4}$ & $4.2 \times 10^{-3}$ & $8.9 \times 10^{-5}$ & $9.0 \times 10^{-4}$ \\
$R^{2}$ & 0.980 & 0.838 & 0.834 & 0.870 & 0.866 & 0.904 \\
$k_{\text {light }}$ & $1.22 \times 10^{-3}$ & $6.03 \times 10^{-3}$ & $5.7 \times 10^{-4}$ & $5.57 \times 10^{-3}$ & $1.7 \times 10^{-5}$ & $5.44 \times 10^{-3}$ \\
$R^{2}$ & 0.992 & 0.917 & 0.946 & 0.968 & 0.894 & 0.946 \\
\hline
\end{tabular}

on the yeast-carbon with photons of energy $(h v)$ equal to or higher than those of band gap results in the excitation of electrons from the valence band (vb) to the conduction band (cb) of the particle, which can produce the electrons $\left(e_{\mathrm{cb}}{ }^{-}\right)$ in the conduction band and the holes $\left(h_{\mathrm{vb}}{ }^{+}\right)$at the valence band edge of the $\mathrm{TiO}_{2}$ (11) [50]. The electrons and holes can migrate to the particle surface of $\mathrm{TiO}_{2}$, where the $h_{\mathrm{vb}}{ }^{+}$can react with the adsorbed $\mathrm{O}_{2}$, surrounded water molecules, and surface hydroxide group, respectively, to generate the highly reactive hydroxyl radicals $\left({ }^{\circ} \mathrm{OH}\right)((12)$ and (13)) and superoxide ions $\mathrm{O}_{2}{ }^{-}$(14). The resulted ${ }^{\circ} \mathrm{OH}$ and $\mathrm{O}_{2}{ }^{-}$are known to be very powerful and indiscriminately oxidizing agents and can oxidize the organic compounds adsorbed onto or very close to the $\mathrm{TiO}_{2}$ surface during the photocatalytic process, resulting in degradation of dye into small units like carbon dioxide and water (15):

$$
\begin{gathered}
\mathrm{TiO}_{2}+h v \longrightarrow \mathrm{TiO}_{2}\left(e_{\mathrm{cb}}^{-}+h_{\mathrm{vb}}{ }^{+}\right) \\
\mathrm{H}_{2} \mathrm{O}+\mathrm{TiO}_{2}\left(h^{+}\right) \longrightarrow \cdot \mathrm{OH}+\mathrm{H}^{+} \\
\mathrm{OH}^{-}+\mathrm{TiO}_{2}\left(h^{+}\right) \longrightarrow{ }^{\cdot} \mathrm{OH} \\
\mathrm{TiO}_{2}\left(e^{-}\right)+\mathrm{O}_{2} \longrightarrow \mathrm{TiO}_{2}+\mathrm{O}_{2}^{\cdot-} \\
\mathrm{O}_{2}^{\cdot-} \text { or } \cdot \mathrm{OH}+\text { dye } \longrightarrow \mathrm{CO}_{2}+\mathrm{H}_{2} \mathrm{O}
\end{gathered}
$$

Simultaneously, the renewed adsorption sites provide a durative supply of $\mathrm{MB}$ molecule for $\mathrm{TiO}_{2}$ particle. Then, the activity of $\mathrm{TiO}_{2} @ y e a s t-c a r b o n$ was successfully recovered after in situ regeneration. The recovered adsorbent could be used for the next adsorption and catalytic reaction cycle. All in all, the combination of both adsorption and heterogeneous catalysis could be regarded as cleaner, greener, favored, and promising technology for removing dye from water. An optimal amount of $\mathrm{TiO}_{2}$ coverage should exist since the coverage rate of the attached $\mathrm{TiO}_{2}$ nanoparticles onto the yeast-carbon surface in the $\mathrm{TiO}_{2} @$ yeast-carbon composite is an important factor for the control of removing dyes. This aspect is currently under investigation.

\section{Conclusions}

In conclusion, $\mathrm{TiO}_{2} @ y e a s t-c a r b o n$ with raspberry-like structure was successfully prepared based on pyrolysis method and was characterized by FE-SEM, EDS, and XRD. The synthetic $\mathrm{TiO}_{2} @$ yeast-carbon was used as adsorbent to remove $\mathrm{MB}$ and CR from aqueous solutions, respectively. FE-SEM images displayed that $\mathrm{TiO}_{2} @ y e a s t-c a r b o n$ microspheres have rough surface morphology and uniform diameter with good dispersity. EDS showed that $\mathrm{TiO}_{2}$ has been already successfully coated on the yeast carbon. The adsorption results showed that $\mathrm{TiO}_{2} @ y e a s t-c a r b o n$ microspheres achieved favorable removal of cationic $\mathrm{MB}$ in comparison with the anionic $\mathrm{CR}$. Equilibrium data for $\mathrm{MB}$ adsorption were best described by the Koble-Corrigan isotherm model. The adsorption of CR onto $\mathrm{TiO}_{2} @ y e a s t-c a r b o n$ showed best agreement with both Freundlich and Koble-Corrigan models. Kinetic data indicated that the adsorption of both $\mathrm{MB}$ and $\mathrm{CR}$ onto $\mathrm{TiO}_{2} @$ yeast-carbon microspheres obeyed pseudo-secondorder kinetic model well. Moreover, regeneration experiments showed that $\mathrm{TiO}_{2} @ y e a s t-c a r b o n$ composites exhibited excellent recycling stability, reusability, and renewable ability. One possible mechanism for regenerating dye-loaded $\mathrm{TiO}_{2} @ y e a s t$ in situ was also proposed. This paper may be useful for further research and practical applications of the novel $\mathrm{TiO}_{2} @ y e a s t$ composite in dye wastewater treatment.

\section{Conflict of Interests}

The authors declare that there is no conflict of interests regarding the publication of this paper.

\section{Acknowledgments}

This work was financially supported by the National Natural Science Foundation of China (no. 21176031), Fundamental Research Funds for the Central Universities (no. 2013G2291015), and National Undergraduate Training Programs for Innovation and Entrepreneurship of Changan University (no. 201410710059).

\section{References}

[1] M. Saquib, M. Abu Tariq, M. M. Haque, and M. Muneer, "Photocatalytic degradation of disperse blue 1 using $\mathrm{UV} / \mathrm{TiO}_{2} / \mathrm{H}_{2} \mathrm{O}_{2}$ process," Journal of Environmental Management, vol. 88, no. 2, pp. 300-306, 2008.

[2] V. Vimonses, S. Lei, B. Jin, C. W. K. Chow, and C. Saint, "Kinetic study and equilibrium isotherm analysis of Congo Red adsorption by clay materials," Chemical Engineering Journal, vol. 148, no. 2-3, pp. 354-364, 2009.

[3] A. Roy, S. Chakraborty, S. P. Kundu, B. Adhikari, and S. B. Majumder, "Adsorption of anionic-azo dye from aqueous solution by lignocellulose-biomass jute fiber: equilibrium, kinetics, and thermodynamics study," Industrial and Engineering Chemistry Research, vol. 51, no. 37, pp. 12095-12106, 2012. 
[4] N. M. Mahmoodi, "Binary catalyst system dye degradation using photocatalysis," Fibers and Polymers, vol. 15, no. 2, pp. 273-280, 2014.

[5] V. S. Mane and P. V. V. Babu, "Studies on the adsorption of Brilliant Green dye from aqueous solution onto low-cost $\mathrm{NaOH}$ treated saw dust," Desalination, vol. 273, no. 2-3, pp. 321-329, 2011.

[6] S. Hisaindee, M. A. Meetani, and M. A. Rauf, "Application of LC-MS to the analysis of advanced oxidation process (AOP) degradation of dye products and reaction mechanisms," TrAC Trends in Analytical Chemistry, vol. 49, pp. 31-44, 2013.

[7] J. Wu, M. A. Eiteman, and S. E. Law, "Evaluation of membrane filtration and ozonation processes for treatment of reactive-dye wastewater," Journal of Environmental Engineering, vol. 124, no. 3, pp. 272-277, 1998.

[8] K. Turhan, I. Durukan, S. A. Ozturkcan, and Z. Turgut, "Decolorization of textile basic dye in aqueous solution by ozone," Dyes and Pigments, vol. 92, no. 3, pp. 897-901, 2012.

[9] S. S. Moghaddam, M. R. A. Moghaddam, and M. Arami, "Coagulation/flocculation process for dye removal using sludge from water treatment plant: optimization through response surface methodology," Journal of Hazardous Materials, vol. 175, no. 1-3, pp. 651-657, 2010.

[10] L. Wang, J. Zhang, R. Zhao, C. Li, Y. Li, and C. Zhang, "Adsorption of basic dyes on activated carbon prepared from Polygonum orientale Linn: equilibrium, kinetic and thermodynamic studies," Desalination, vol. 254, no. 1-3, pp. 68-74, 2010.

[11] Q. H. Hu, S. Z. Qiao, F. Haghseresht, M. A. Wilson, and G. Q. Lu, "Adsorption study for removal of basic red dye using bentonite," Industrial \& Engineering Chemistry Research, vol. 45, no. 2, pp. 733-738, 2006.

[12] D. Sun, X. Zhang, Y. Wu, and X. Liu, "Adsorption of anionic dyes from aqueous solution on fly ash," Journal of Hazardous Materials, vol. 181, no. 1-3, pp. 335-342, 2010.

[13] G. K. Sarma, S. SenGupta, and K. G. Bhattacharyya, "Methylene blue adsorption on natural and modified clays," Separation Science and Technology, vol. 46, no. 10, pp. 1602-1614, 2011.

[14] A. A. Ahmad, A. Idris, and B. H. Hameed, "Organic dye adsorption on activated carbon derived from solid waste," Desalination and Water Treatment, vol. 51, no. 13-15, pp. 25542563, 2013.

[15] M. Jayarajan, R. Arunachalam, and G. Annadurai, "Agricultural wastes of Jackfruit peel nano-porous adsorbent for removal of Rhodamine dye," Asian Journal of Applied Sciences, vol. 4, no. 3, pp. 263-270, 2011.

[16] D. Uçar and B. Armağan, "The removal of reactive black 5 from aqueous solutions by cotton seed shell," Water Environment Research, vol. 84, no. 4, pp. 323-327, 2012.

[17] R. Nacco and E. Aquarone, "Preparation of active carbon from yeast," Carbon, vol. 16, no. 1, pp. 31-34, 1978.

[18] Z. Guan, L. Liu, L. He, and S. Yang, "Amphiphilic hollow carbonaceous microspheres for the sorption of phenol from water," Journal of Hazardous Materials, vol. 196, pp. 270-277, 2011.

[19] W. Jiang, J. A. Joens, D. D. Dionysiou, and K. E. O’Shea, "Optimization of photocatalytic performance of $\mathrm{TiO}_{2}$ coated glass microspheres using response surface methodology and the application for degradation of dimethyl phthalate," Journal of Photochemistry and Photobiology A: Chemistry, vol. 262, pp. 713, 2013.
[20] J. Matos, A. Garcia, T. Cordero, J.-M. Chovelon, and C. Ferronato, "Eco-friendly $\mathrm{TiO}_{2}-\mathrm{AC}$ photocatalyst for the selective photooxidation of 4-chlorophenol," Catalysis Letters, vol. 130, no. 3-4, pp. 568-574, 2009.

[21] D. Yu, B. Bo, and H. Yunhua, "Fabrication of $\mathrm{TiO}_{2}$ @yeastcarbon hybrid composites with the raspberry-like structure and their synergistic adsorption-photocatalysis performance," Journal of Nanomaterials, vol. 2013, Article ID 851417, 8 pages, 2013.

[22] M. Liu, L. Piao, W. Lu et al., "Flower-like $\mathrm{TiO}_{2}$ nanostructures with exposed 001 facets: facile synthesis and enhanced photocatalysis," Nanoscale, vol. 2, no. 7, pp. 1115-1117, 2010.

[23] S. Feng, J. Yang, M. Liu et al., "Hydrothermal growth of doublelayer $\mathrm{TiO}_{2}$ nanostructure film for quantum dot sensitized solar cells," Thin Solid Films, vol. 520, no. 7, pp. 2745-2749, 2012.

[24] B. H. Hameed, A. T. M. Din, and A. L. Ahmad, "Adsorption of methylene blue onto bamboo-based activated carbon: kinetics and equilibrium studies," Journal of Hazardous Materials, vol. 141, no. 3, pp. 819-825, 2007.

[25] Y.-P. Chang, C.-L. Ren, J.-C. Qu, and X.-G. Chen, "Preparation and characterization of $\mathrm{Fe}_{3} \mathrm{O}_{4}$ /graphene nanocomposite and investigation of its adsorption performance for aniline and $p$ chloroaniline," Applied Surface Science, vol. 261, pp. 504-509, 2012.

[26] J. Rivera-Utrilla, I. Bautista-Toledo, M. A. Ferro-Garca, and C. Moreno-Castilla, "Activated carbon surface modifications by adsorption of bacteria and their effect on aqueous lead adsorption," Journal of Chemical Technology and Biotechnology, vol. 76, no. 12, pp. 1209-1215, 2001.

[27] L. C. Juang, C. C. Wang, and C. K. Lee, "Adsorption of basic dyes onto MCM-41," Chemosphere, vol. 64, no. 11, pp. 1920-1928, 2006.

[28] H.-X. Ou, Y.-J. Song, Q. Wang et al., "Adsorption of lead(II) by silica/cell composites from aqueous solution: kinetic, equilibrium, and thermodynamics studies," Water Environment Research, vol. 85, no. 2, pp. 184-191, 2013.

[29] I. Langmuir, "The adsorption of gases on plane surfaces of glass, mica and platinum," The Journal of the American Chemical Society, vol. 40, no. 9, pp. 1361-1403, 1918.

[30] T. W. Weber and R. K. Chakravorti, "Pore and solid diffusion models for fixed-bed adsorbers," AIChE Journal, vol. 20, no. 2, pp. 228-238, 1974.

[31] L. Huang, Y. Sun, W. Wang, Q. Yue, and T. Yang, "Comparative study on characterization of activated carbons prepared by microwave and conventional heating methods and application in removal of oxytetracycline (OTC)," Chemical Engineering Journal, vol. 171, no. 3, pp. 1446-1453, 2011.

[32] H. M. F. Freundlich, "Uber die adsorption in losungen," Zeitschrift Für Physikalische Chemie. International Journal of Research in Physical Chemistry and Chemical Physics A, vol. 57, pp. 385-470, 1906.

[33] L. Chen and B. Bai, "Equilibrium, kinetic, thermodynamic, and in situ regeneration studies about methylene blue adsorption by the raspberry-like $\mathrm{TiO}_{2} @ y e a s t$ microspheres," Industrial and Engineering Chemistry Research, vol. 52, no. 44, pp. 15568-15577, 2013.

[34] I. D. Mall, V. C. Srivastava, N. K. Agarwal, and I. M. Mishra, "Removal of congo red from aqueous solution by bagasse fly ash and activated carbon: kinetic study and equilibrium isotherm analyses," Chemosphere, vol. 61, no. 4, pp. 492-501, 2005. 
[35] M. I. Tempkin and V. Pyzhev, "Kinetics of ammonia synthesis on promoted iron catalysts," Acta Physiochim (URSS), vol. 12, no. 3, pp. 217-222, 1940.

[36] P. Wu, W. Wu, S. Li et al., "Removal of $\mathrm{Cd}^{2+}$ from aqueous solution by adsorption using Fe-montmorillonite," Journal of Hazardous Materials, vol. 169, no. 1-3, pp. 824-830, 2009.

[37] W. Jiang, M. Pelaez, D. D. Dionysiou, M. H. Entezari, D. Tsoutsou, and K. O'Shea, "Chromium(VI) removal by maghemite nanoparticles," Chemical Engineering Journal, vol. 222, pp. 527533, 2013.

[38] M. Zhang, H. Zhang, D. Xu et al., "Removal of ammonium from aqueous solutions using zeolite synthesized from fly ash by a fusion method," Desalination, vol. 271, no. 1-3, pp. 111-121, 2011.

[39] M. Hamidpour, M. Kalbasi, M. Afyuni, and H. Shariatmadari, "Kinetic and isothermal studies of cadmium sorption onto bentonite and zeolite," International Agrophysics, vol. 24, no. 3, pp. 253-259, 2010.

[40] L. Ai, M. Li, and L. Li, "Adsorption of methylene blue from aqueous solution with activated carbon/cobalt ferrite/alginate composite beads: kinetics, isotherms, and thermodynamics," Journal of Chemical \& Engineering Data, vol. 56, no. 8, pp. 34753483, 2011.

[41] T. Liu, Y. Li, Q. Du et al., "Adsorption of methylene blue from aqueous solution by graphene," Colloids and Surfaces B: Biointerfaces, vol. 90, no. 1, pp. 197-203, 2012.

[42] M. Doğan, M. Alkan, and Y. Onganer, "Adsorption of methylene blue from aqueous solution onto perlite," Water, Air, and Soil Pollution, vol. 120, no. 3-4, pp. 229-248, 2000.

[43] B. H. Hameed and A. A. Ahmad, "Batch adsorption of methylene blue from aqueous solution by garlic peel, an agricultural waste biomass," Journal of Hazardous Materials, vol. 164, no. 2-3, pp. 870-875, 2009.

[44] C. Namasivayam and D. Kavitha, "Removal of Congo Red from water by adsorption onto activated carbon prepared from coir pith, an agricultural solid waste," Dyes and Pigments, vol. 54, no. 1, pp. 47-58, 2002.

[45] L. Wang and A. Wang, "Adsorption characteristics of Congo red onto the chitosan/montmorillonite nanocomposite," Journal of Hazardous Materials, vol. 147, no. 3, pp. 979-985, 2007.

[46] S. A. Idris, K. M. Alotaibi, T. A. Peshkur, P. Anderson, M. Morris, and L. T. Gibson, "Adsorption kinetic study: effect of adsorbent pore size distribution on the rate of Cr (VI) uptake," Microporous and Mesoporous Materials, vol. 165, pp. 99-105, 2013.

[47] W. Guan, J. Pan, H. Ou et al., "Removal of strontium(II) ions by potassium tetratitanate whisker and sodium trititanate whisker from aqueous solution: equilibrium, kinetics and thermodynamics," Chemical Engineering Journal, vol. 167, no. 1, pp. 215222, 2011.

[48] L. F. Liu, P. H. Zhang, and F. L. Yang, "Adsorptive removal of 2,4DCP from water by fresh or regenerated chitosan/ACF/TiO 2 membrane," Separation and Purification Technology, vol. 70, no. 3, pp. 354-361, 2010.

[49] B. Bai, N. Quici, Z. Li, and G. L. Puma, "Novel one step fabrication of raspberry-like $\mathrm{TiO}_{2} @ y e a s t$ hybrid microspheres via electrostatic-interaction-driven self-assembled heterocoagulation for environmental applications," Chemical Engineering Journal, vol. 170, no. 2-3, pp. 451-456, 2011.

[50] V. K. Gupta, R. Jain, A. Mittal, M. Mathur, and S. Sikarwar, "Photochemical degradation of the hazardous dye Safranin-T using $\mathrm{TiO} 2$ catalyst," Journal of Colloid and Interface Science, vol. 309, no. 2, pp. 464-469, 2007. 

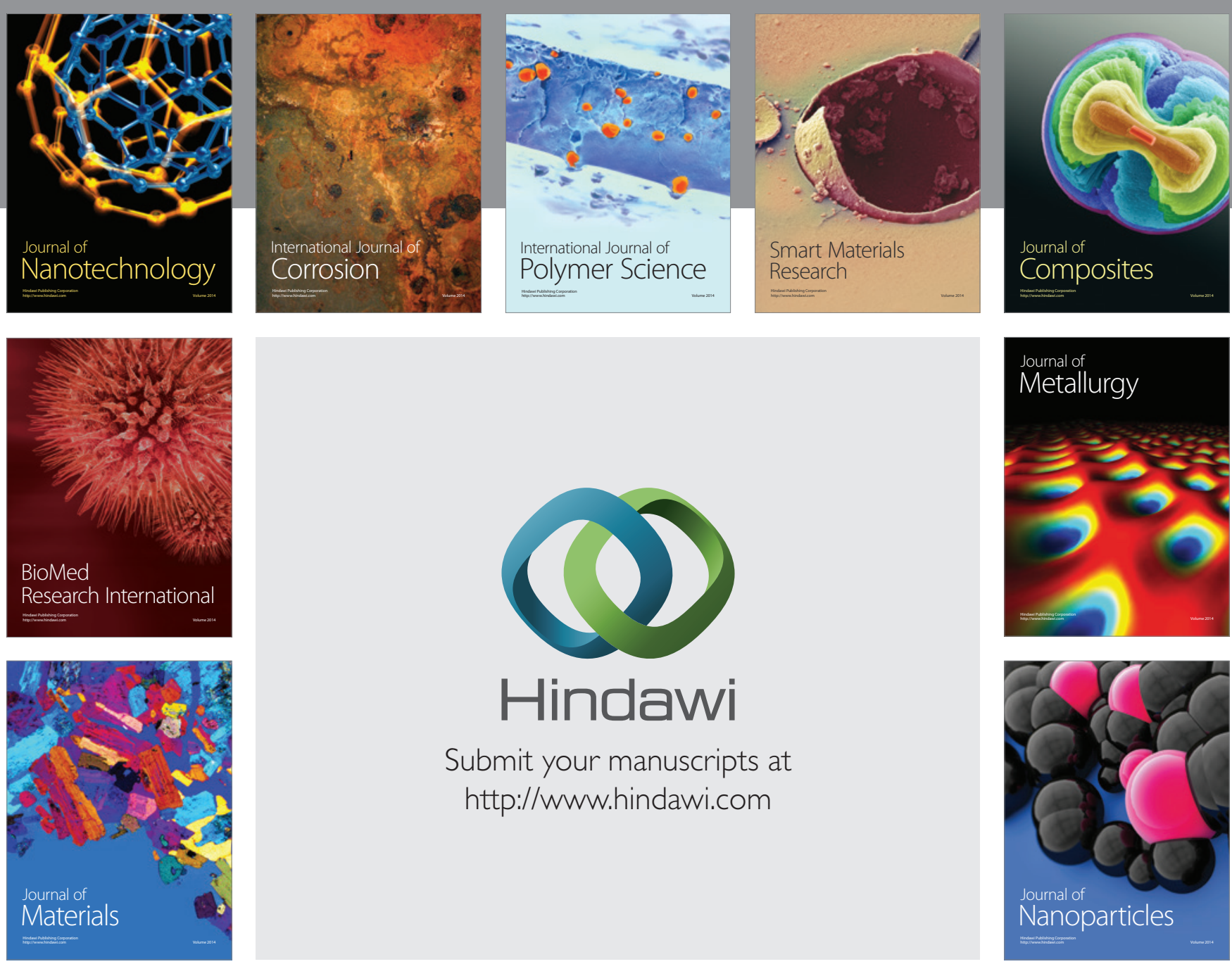

Submit your manuscripts at http://www.hindawi.com
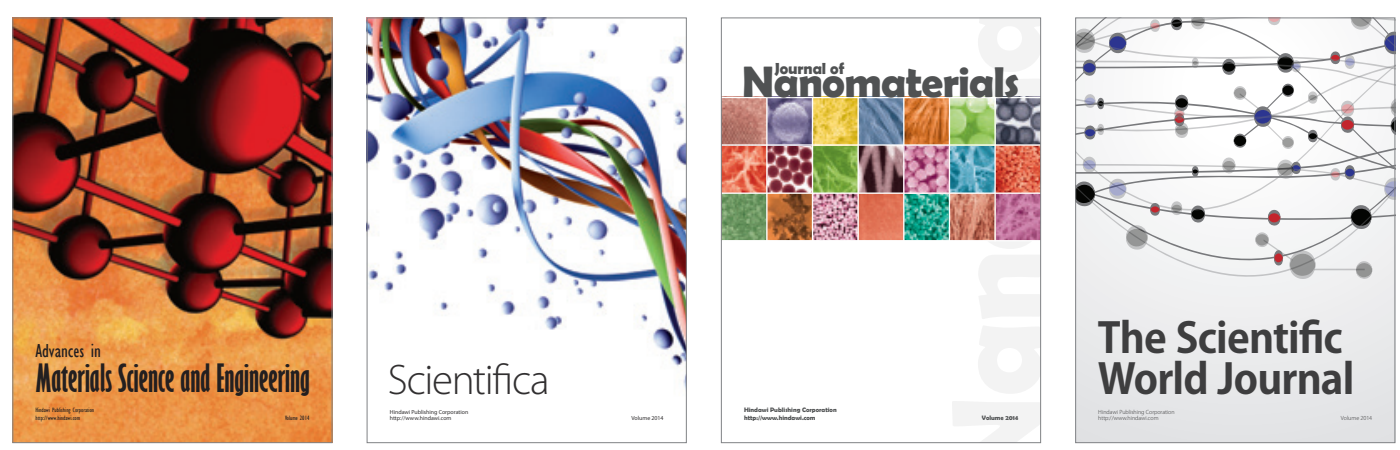

\section{The Scientific World Journal}
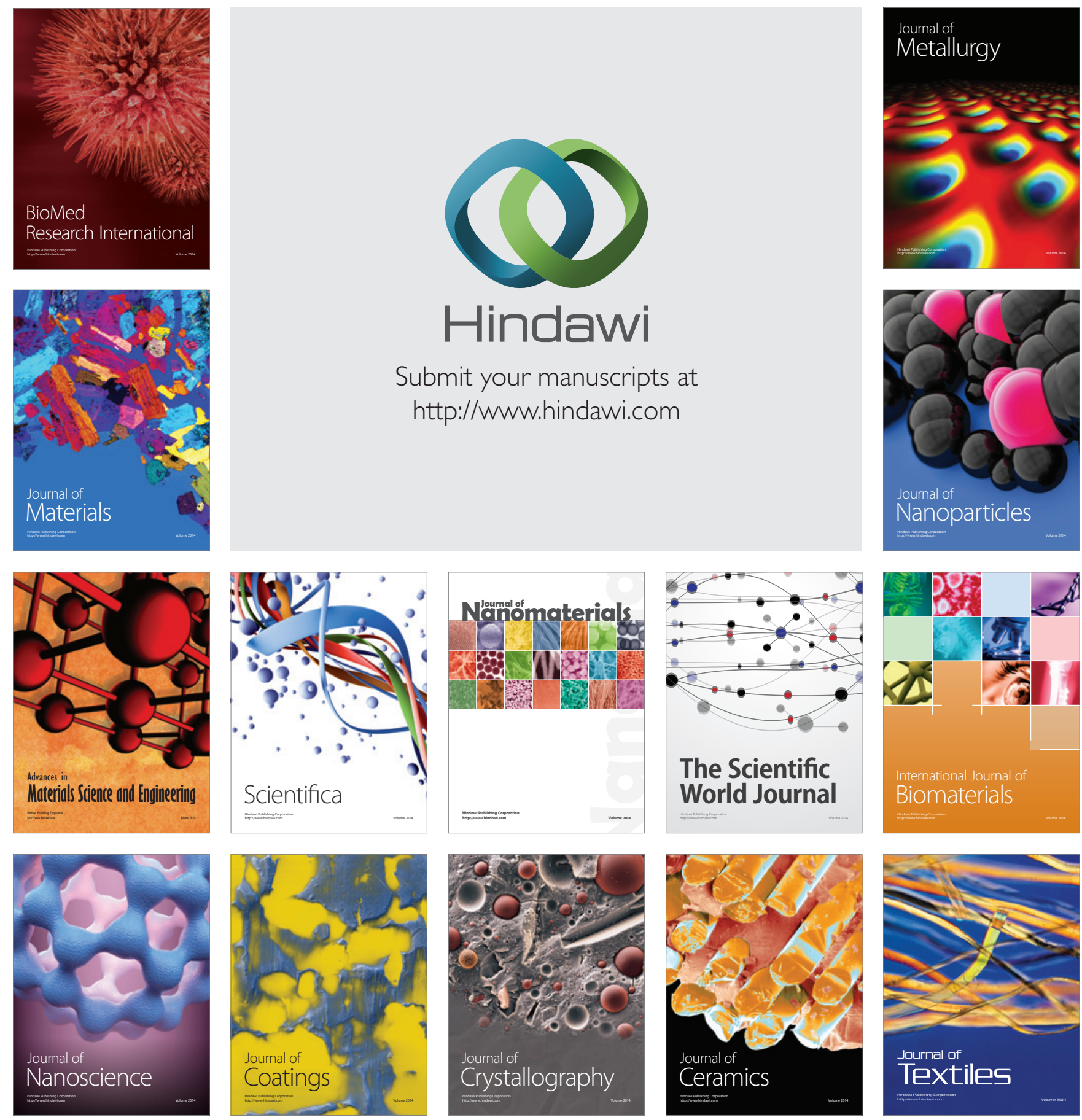